\title{
The potential of polymers of intrinsic microporosity (PIMs) and PIM/graphene composites for pervaporation membranes
}

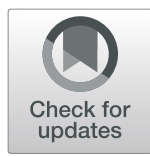

\author{
Richard A. Kirk', Maia Putintseva², Alexey Volkov² and Peter M. Budd ${ }^{1 *}$ (D)
}

\begin{abstract}
Pervaporation (PV), a membrane process in which the feed is a liquid mixture and the permeate is removed as a vapour, offers an energy-efficient alternative to conventional separation processes such as distillation, and can be applied to mixtures that are difficult to separate, such as azeotropes. Here the principles of pervaporation and its industrial applications are outlined. Two classes of material that show promise for use in PV membranes are described: Polymers of intrinsic microporosity (PIMs) and 2D materials such as graphene. The literature regarding PV utilizing the prototypical PIM (PIM-1) and it hydrophilic hydrolysed form (CPIM-1) is reviewed. Self-standing PIM-1 membranes give competitive results compared to other membranes reported in the literature for the separation of alcohols and other volatile organic compounds from aqueous solution, and for organic/organic separations such as methanol/ethylene glycol and dimethyl carbonate/methanol mixtures. Blends of CPIM-1 with conventional polymers improve the flux for dehydration of alcohols. The incorporation of fillers, such as functionalised graphene-like fillers, into PIM-1 to form mixed matrix membranes can enhance the separation performance. Thin film composite (TFC) membranes enable very high fluxes to be achieved when a suitable support with high surface porosity is utilised. When functionalised graphene-like fillers are introduced into the selective layer of a TFC membrane, the lateral size of the flakes needs to be carefully controlled. There is a wide range of PIMs and 2D materials yet to be explored for PV applications, which offer potential to create bespoke membranes for a wide variety of organic/aqueous and organic/organic separations.
\end{abstract}

Keywords: Membrane, Pervaporation, Polymer of intrinsic microporosity, Graphene, Graphene oxide

\section{Introduction}

Pervaporation is a membrane process that allows the separation of azeotropic and other liquid mixtures that are difficult to separate by conventional methods such as distillation. There is a need for membrane materials that offer good selectivity and high flux for a wide range of industrially important separations. In 2004, two developments at the University of Manchester gave rise to materials that have attracted attention for use in pervaporation membranes and for other applications. Firstly, in Chemistry, a new class of high free volume, membraneforming polymer was reported, referred to as "Polymers of Intrinsic Microporosity" or "PIMs" [1, 2]. Secondly, in

* Correspondence: Peter.Budd@manchester.ac.uk

'School of Chemistry, University of Manchester, Manchester M13 9PL, UK Full list of author information is available at the end of the article
Physics, it was reported that single-layer graphene had been isolated [3].

This review first provides background information about the fundamentals of the pervaporation process and its development for industrial applications, about the development and applications of PIMs, and about the history and applications of graphene and its oxidised form, graphene oxide. It then summarises the literature on pervaporation membranes utilising PIMs, with a special emphasis on the combination of PIMs with graphene-based fillers. Finally, the prospects and opportunities for PIM-based pervaporation membranes are considered.

\section{Pervaporation}

Fundamentals

Pervaporation (PV) was first reported by Kober et al. in 1917 [4] and has since become a well-established separation 
process where a mixture of miscible liquids is put into contact with a membrane [5]. As the name suggests, the overall process involves permeation of a component of the mixture through the membrane, followed by evaporation on the permeate side [6]. The permeate vapour is subsequently condensed. The driving force of $\mathrm{PV}$ is a difference in the effective partial vapour pressure between the feed and permeate sides of the membrane, which gives rise to a chemical potential gradient. This is achieved by applying a vacuum or sweep gas on the permeate side. A typical PV process is shown schematically in Fig. 1.

The performance of a membrane is described in terms of its productivity (the throughput of molecules through the membrane) as well as by its ability to separate the components in the feed mixture. In PV studies, the productivity is often expressed in terms of a total mass flux, $J_{\text {total }}$, calculated using

$$
J_{\text {total }}=\frac{m}{A t}
$$

where $m$ is the mass of permeate collected over time $t$ for a membrane of area $A$. From the composition of the permeate, the flux of a component, $J_{i}$, where $i$ indicates the component in question, can then be determined. Component fluxes can be expressed in either mass or molar terms. The flux depends on the conditions of the experiment as well as on the driving force across the membrane and on the membrane thickness, $l$. To obtain results that are normalised for the membrane thickness, the flux can simply be multiplied by the thickness. Membrane materials are best compared in terms of permeabilities, $P_{i}$, which are normalised for the driving force as well as for membrane thickness:

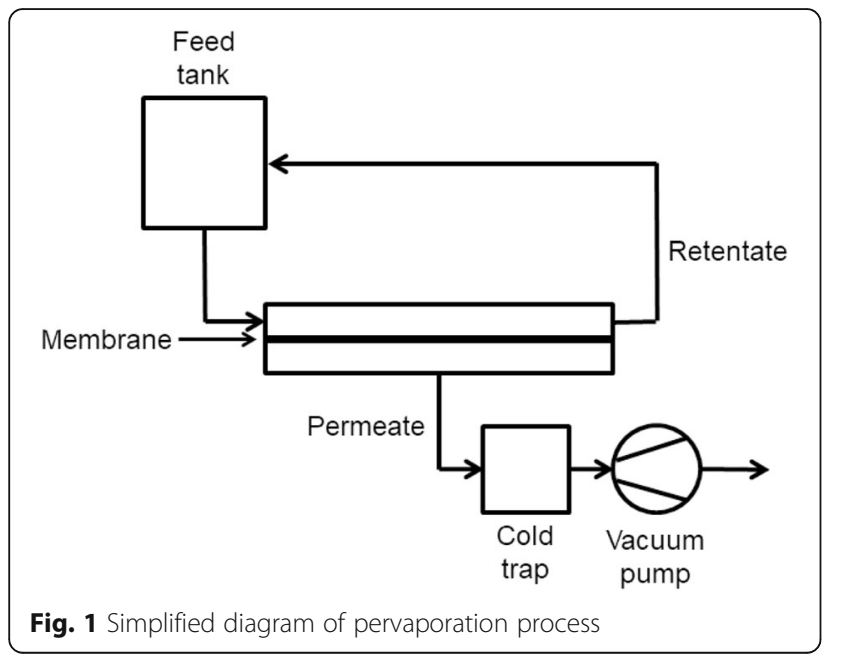

$$
P_{i}=\frac{J_{i} l}{\left(f_{i, f}-f_{i, p}\right)}
$$

where $f_{i, f}$ and $f_{i, p}$ are the fugacities of component $i$ in the feed and permeate, respectively. For an ideal gas, fugacity may be replaced by partial pressure, but many vapours of interest for PV show nonideal behaviour.

For a two component mixture, the selectivity of a membrane, $\alpha$, may be expressed as a ratio of permeabilities.

$$
\alpha=\frac{P_{i}}{P_{j}}
$$

It has been argued that this is the best way to describe separating ability $[7,8]$. Nevertheless, it is more common in PV studies to report a separation factor, also symbolised by $\alpha$ in older literature, but nowadays generally symbolised by $\beta$ :

$$
\beta=\frac{\left(Y_{i} / Y_{j}\right)}{\left(X_{i} / X_{j}\right)}
$$

where $Y_{i} / Y_{j}$ is the weight ratio of the components in the permeate and $X_{i} / X_{j}$ is the corresponding ratio in the feed. Other ways of describing the separating ability include an enrichment factor, which is the ratio of concentrations of the preferentially permeating component in permeate and feed [9], and which is also sometimes symbolised by $\beta$. Care must be taken when comparing pervaporation data from different sources to understand the basis of the results reported.

Typically, a trade-off between productivity and separating ability is observed. The overall performance of a membrane for a pervaporative separation can be quantified using a pervaporation separation index, PSI:

$$
\mathrm{PSI}=J_{\text {total }}(\beta-1)
$$

If there is either no flux or no separation, then the PSI will be zero.

A number of factors contribute to the separation obtained in PV. Firstly, as PV involves a phase change from liquid to vapour, there is the separation associated with the vapour-liquid equilibrium. Secondly, there is a contribution from the membrane itself, which may enhance that from vapour-liquid equilibrium, or in some cases override it. In addition, there are effects linked to the effectiveness of the membrane module and to the operating conditions [10].

PV can often be understood in terms of a solutiondiffusion model. This involves: (1) Dissolution or sorption 
of the permeating species in the membrane on the feed side, (2) diffusion through the membrane, and (3) desorption at the permeate side. Separation due to the membrane can be enhanced either through sorption selectivity, which commonly favours the more condensable or more strongly interacting molecules, or through diffusion selectivity, which depends on the size and shape of the permeating molecules and on the distribution of free volume within the membrane material [11]. More comprehensive models of pervaporation take account of additional factors, such as the resistance associated with a boundary layer on the feed side of the membrane, which has a different composition to the bulk of the feed mixture [10].

\section{Development for industrial applications}

The use of PV processes for industrial applications has increased steadily over recent decades, with initial applications being explored as early as 1958 by Binning et al. $[12,13]$ and patents being published in the 1960 s by Binning et al. [14] and Loeb et al. [15], then being further developed in the years afterwards $[6,16,17]$. During that time it was noted that the fluxes obtained from the membranes then available were too low to be economically viable for industrial use [18]. This problem was alleviated in 1985 by Gesellschaft für Trenntechnik (GFT) with the development of a composite membrane, made from poly (vinyl alcohol) thinly layered onto a porous support material (polyacrylonitrile) [17]. Since then work towards industrially relevant PV materials has continued. With the more prevalent distillation separations being energy intensive processes, PV has been utilised and developed as a greener and more cost effective method of liquid separation and extraction $[11,19,20]$. PV has been investigated for both organic-organic and aqueousorganic separations, as discussed below. Membranes based on PIMs show promise for industrial applications due to their intrinsic microporosity that gives rise to good fluxes and selectivities. The future development of membranes for PV will benefit from current research on PIM membranes for other types of separation, such as the development of hollow fibre membranes for gas separation $[21,22]$.

\section{Organic-organic separations}

Organic-organic separations via PV have been used extensively on four main types of mixture: (i) polar/nonpolar, (ii) aromatic/alicyclic, (iii) aromatic/aliphatic, and (iv) isomers. The first reported use of PV for organicorganic separation was the removal of $n$-hexane from iso-octane in 1961 by Binning et al. [13].

The separation of polar/non-polar mixtures was achieved in 1976 by Aptel et al. [23], who used polytetrafluoroethylene films grafted with $\mathrm{N}$-vinylpyrrolidone to separate mixtures such as methanol/toluene and methanol/benzene. This followed from some earlier work $[24,25]$. There has since been a great deal of data published showing an array of polymer membranes that can be used for the separation of polar/non-polar solvent mixtures, predominantly alcohols from aromatics [26]. The highly selective separation of methanol from cyclohexane (separation factor $\beta_{\text {methanol/cyclohexane }}$ up to 2000) using a composite membrane has also been achieved [27]. Good fluxes up to $10 \mathrm{~kg} \mathrm{~m}^{-2} \mathrm{~h}^{-1}$ for methanol/toluene separation have been accomplished using a poly (acrylic acid)/poly (vinyl alcohol) blend [28]. Furthermore, it has been demonstrated that the flux and the selectivity of methanol/toluene separation can be tuned through the use of other polymer membranes [29]. Work towards optimising performance is still ongoing, with recent developments using aromatic copolyamides which offer improved flux and selectivities when compared to previous membranes [30].

The use of PV for aromatic/alicyclic separations has been investigated since the first commercialisation attempts in the 1960s [31, 32]. Benzene/cyclohexane mixtures are commonly encountered in industry, making their separation of interest. They are however, particularly difficult to separate and so there has been a great deal of focus on the use of PV membranes to alleviate this problem [26, 33]. Recently developed poly (vinyl chloride)/polystyrene blended membranes offer good performances for the separation of the two compounds

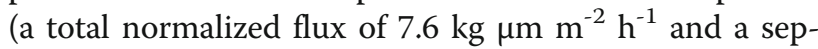
aration factor of 18.33) [34].

The separation of aromatic/aliphatic mixtures can be challenging, owing to the similarities in both physical and chemical properties between certain aromatics and aliphatics [35]. PV was again considered for this application as far back as the 1970s [36]. Whilst there is still plenty of literature offering decent separative performances from a range of membranes, there has yet to be any industrial adoption of pervaporation for aromatic/ aliphatic separations $[26,35]$. This is likely due to the poor performances of the developed membranes on a continuous, large scale [35].

With the ability to separate mixtures of compounds with very similar properties, PV can also be used in the separation of isomer mixtures [26]. The first example of this dates back to 1982, for the separation of xylene isomers using cellulose based membranes [37]. The initial process gave poor selectivity, which has later been improved [38-40]. PV has also been used for the separation of short chain aliphatics, with the separation of $\mathrm{C}_{6}$ and $\mathrm{C}_{4}$ isomers being noted in the literature [41, 42].

\section{Aqueous-organic separations}

Aqueous-organic PV separations can be divided into two groups: (i) The removal of organics from aqueous 
solutions and (ii) the removal of water from organics (dehydration), with the latter being the most prevalent of the two [43].

The removal of organics from water is often desired for environmental reasons. Volatile organic compounds (VOCs) may occur in aqueous media due to pollution from both man-made and natural sources [44]. Therefore, VOC removal via PV has gained attention over the past decades, particularly for aqueous systems which contain very small quantities of VOCs present, whose low solubilities in water make distillation unviable [45]. The first reported use of PV for VOC removal was in 1970 by Cole et al. [46], with numerous reports since then showing further developments in the field [45]. A great number of PV membranes investigated for the removal of VOCs have been formed from organophilic materials such as poly[1-(trimethylsilyl)-1-propyne] (PTMSP), polydimethylsiloxane (PDMS), poly (ether-block-amide) (PEBA), and polyvinylidene fluoride (PVDF) [47-54], with many of these polymers and their derivatives being used in industrial settings [55-58]. The removal of organics from water is also of interest for industrial biotechnology, in particular for the recovery of products such as ethanol, butanol and acetone from fermentation broths, where the concentration of organics is low because of their toxicity towards the microorganisms used for fermentation $[59,60]$.

In contrast to situations in which low concentrations of organic compounds need to be removed from aqueous media, water can be removed from organics via PV to allow for dehydration of solvents. This is particularly valuable for solvents which form azeotropes (constant boiling mixtures) with water. Traditionally, azeotropic distillation was employed with the addition of entrainers to aid in breaking the azeotropes [61-63]. The main drawback of this method is that the addition of an entrainer or an entrainer mixture adds an additional impurity into the solvent, which can also prove difficult to remove entirely, rendering the solvent unsuitable for high purity applications [64]. With PV relying on the separative ability of a membrane, there is no need for additives. The majority of PV applications for dehydration are for the drying of alcohols such as methanol, ethanol and butanol [64-66]. In recent years, the development of PV membranes for such applications has been studied extensively, with the fabrication of membranes from a large range of hydrophilic materials [67-72]. Whilst there have been many materials used in alcohol dehydration processes, research has taken a distinct shift towards the use of chitosan based membranes [64, 67, 70, 73-76]. The application of PV for dehydration is not limited to alcohols. Membranes have been developed which have allowed the drying of other industrially useful solvents such as acetic acid [64, 77-79], tetrahydrofuran $[64,77,80]$, acetone $[64,77,81]$ and acetonitrile [82].
Nowadays, membrane materials play a key role in the development of membrane processes, defining the separation performance. There is a need for novel materials with better separation characteristics to enable industrially viable processes. PIMs and 2D materials, between them, offer significant potential for achieving enhanced separation performances.

\section{Polymers of Intrinsic Microporosity (PIMs) Discovery, design and synthesis of PIMs}

The first glassy polymer with high fractional free volume was a disubstituted polyacetylene, PTMSP, reported by Masudo et al. in 1984 [83]. Due to the combination of double bonds in the main chain and the presence of bulky side groups, disubstituted polyacetylenes have a rigid structure that results in loose macrochain packing, giving PTMSP incredibly high permeability towards small gases. Despite membranes based on PTMSP and other polyacetylenes with bulky substituents being well studied, these polymers have not found commercial application because of their inherent disadvantages, including ageing, a dramatic decrease of porosity with time [84], and fouling [85].

A breakthrough in the design of high permeability glassy polymers was the synthesis of polybenzodioxins incorporating spiro-centres, which then became known as polymers of intrinsic microporosity (PIMs). In this context, "microporosity" refers to pores of dimensions smaller than $2 \mathrm{~nm}$ [86]. PIMs are defined as having 'a continuous network of interconnected intermolecular voids, which forms as a direct consequence of the shape and rigidity of the component macromolecule' [87, 88]. Due to their inherent rigidity and contorted shape, the polymer chains cannot fill space efficiently in the same way that typical linear polymers can, giving rise to their intrinsic microporosity. The first reported PIM by McKeown and Budd et al. in 2004 [1], appropriately named PIM-1, was the product of a nucleophilic aromatic substitution reaction between the two commercially available monomers 5,5',6,6'-tetrahydroxy-3,3,3',3'tetramethyl-1,1'-spirobisindane (SBI) and tetrafluoroterephthalonitrile (TFTPN) (Fig. 2).

PIMs allow for the tuning of their properties through modification of the polymer design and synthesis. The nitrile groups in PIM-1 can be chemically modified to yield a range of polymers with tailored properties. Base catalysed hydrolysis of PIM-1 gives a more hydrophilic polymer, which generally has a mixture of amide and carboxylic acid groups [89]. Other modifications include thioamide [90], tetrazole [91, 92], amine [93] and hydroxyalkylaminoalkylamide [94]. The design and synthesis of novel, highly rigid monomers allows for the formation of PIMs with tailored properties via the introduction of inflexible, bulky structural units in place of spirobisindane; 
<smiles>CC1(C)Cc2cc3c(cc2-c2cc4c(cc21)Oc1c(C#N)c2c(c(C#N)c1O4)OCCO2)C(C)(C)Cc1cc2c(cc1C3(C)C)C(C)(C)CC21c2cc(O)c(O)cc2C2(CC(C)(C)c3cc(O)c(O)cc32)CC1(C)C</smiles>

Fig. 2 Synthesis of PIM-1

with triptycenes, spirobifluorenes and ethanoanthracenes as prominent examples [95-98].

PIM preparation is not only limited to the polydibenzodioxin formation seen in PIM-1. Polyimide (PI) synthesis has been employed for the formation of high performance polyimide-PIMs (PIM-PIs) [99-105]. Unlike polydibenzodioxins, the PIM-PIs are not ladder-like in structure and require bulky substituents adjacent to the imide linkages to prevent rotation and increase the rigidity of the polymer chains.

Tröger's Base (TB), a fused bicyclic molecule first synthesised by Julius Tröger in 1887 [106], with full structural elucidation by Spielman and Wilcox et al. $[107,108]$, has been used in the formation of PIMs, due to the rigid, contorted structure of the aromatic rings fused together through a bicyclic methylene system with nitrogen atoms at the bridgeheads. The first TB-PIM was reported by McKeown et al. [109], where diamine monomers were subjected to condensation reactions with a formaldehyde source mediated by strong acid. Further development of TB-PIMs has continued [110113]. The rigid and contorted shape of TB makes it an ideal candidate for incorporation as a structural unit in monomers for PIM synthesis. TB has been used to build novel monomers for use in benzodixane and polyimide synthesis, making it a versatile structure in PIM formation $[102,114,115]$.

\section{Applications of PIMs}

The wide and versatile range of PIMs has been adopted into a broad range of potential applications. The predominant application investigated for PIMs over the past decade has been for gas separation membranes. The high internal surface areas of PIMs that arise due to their inherent microporosity give PIM membranes high permeabilities towards a range of gases, whilst also maintaining reasonable selectivities [116]. A common challenge in membrane technology is to obtain a balance between selectivity and permeability, as demonstrated in 1991 by Robeson [117], who defined the upper bounds of performance that had been achieved with polymeric membranes for key gas pairs. The upper bounds were revised in 2008 [118] to accommodate PIMs and other new materials. In recent years there has been a great deal of work on new developments towards the formation of even higher performance PIMs for gas separation [95-98, 100-102, 105, 110-115, 119-122], which led to a further revision of the upper bounds in 2015 for certain gas pairs $[105,111,123]$. The potential shown as gas separation membranes has meant that they have also gained industrial attention for processes such as gas enrichment, as well as carbon capture during post combustion processes, and hydrogen storage [124-129].

PIMs have also seen applications towards heterogeneous catalysis, largely focussing on the use of networkPIMs that contain catalytic sites. These network PIMs have been used to perform Suzuki couplings, sulphur formation reactions and oxidation reactions [130-133]. Furthermore, PIMs have been employed as sensors due to both their intrinsic microporosity and their unique optical fluorescence. PIM-1 has been used as lightemitters and optical sensors to detect low traces of organic vapours as well as some explosive compounds [134-136]. The addition of dyes into films of PIM-3 allowed for the detection of ethanol [134]. PIM-1 has been commercialised in a sensor that visually indicates the presence of excess organic vapour in a filter for personal protection equipment [135].

Finally, PIMs have found applications in liquid phase separations, such as the separation of unwanted or harmful compounds found in wastewater streams. The removal of phenol from aqueous solution has been studied via adsorption into network PIMs [130, 131]. PIM-1 and hydrolysed PIM-1 (cPIM-1) have been investigated for PV separation processes, which will be discussed in greater detail below. PIMs offer particular advantages for PV because of their intrinsically microporous nature. As discussed above, transport in PV can generally be understood in terms of a solution-diffusion mechanism and the sorption selectivity usually plays a major role in the overall selectivity. Molecules with higher affinity can be accommodated within the free volume elements of a PIM with only minor swelling of the polymeric matrix, enhancing the sorption capacity compared to conventional 
glassy polymers and polymer rubbers. At the same time, the microporous nature allows greater diffusion of molecules across the membrane.

\section{Graphene}

\section{Discovery and formation of graphene}

Graphene is a sheet-like arrangement of $\mathrm{sp}^{2}$-hybridized carbon forming a two-dimensional (2D) honeycomb network. It is the simplest form of pure carbon-based materials that include single and multi-walled carbon nanotubes, fullerenes and graphite. Graphene has many extraordinary and useful thermal, mechanical, and electrical properties, making it an interesting material, drawing a great deal of attention in recent years [137]. Graphite, an extended three-dimensional (3D) material of stacked layers of graphene, has been studied extensively [138], and graphene was first studied theoretically as early as 1947 by Philip Wallace [139]. However, single layers of graphene were not isolated until 2004, with work at the University of Manchester by Geim et al. [3], mechanically exfoliating graphite to achieve the isolation of 2D crystals of single-layer graphene. Graphene has since been produced in differing formats (graphene oxide, reduced graphene oxide and graphene nanomaterials being key examples), each of which have been investigated for a range of applications. Graphene oxide (GO) is a high oxygen content version of graphene with a $\mathrm{C} / \mathrm{O}$ atomic ratio between 2 and 3. GO is prepared from graphite by oxidation and exfoliation that is followed by extensive oxidative modification of the basal plane. The oxidation is most commonly performed using the Hummers' method or modified versions of it, whereby potassium permanganate is used as the oxidising agent [140, 141]. Reduced graphene oxide (rGO) is GO which has been reduced chemically, photo-chemically, thermally or photo-thermally to reduce its oxygen content, as the name suggests. Microwave or microbial/bacterial methodology can also be used to achieve the same result [141]. Graphene nanomaterials are a group of 2D materials that include graphene nanosheets, graphene nanoribbons and graphene nanoflakes with a thickness and/or lateral dimension of less than 100 nanometers [141].

\section{Applications of graphene and graphene oxide}

Although graphene itself has only recently been isolated, there is a long history of materials that utilise the surface properties of graphene. Activated carbons (ACs) have been used throughout antiquity, dating back to ancient Egypt, the Roman empire and ancient Greece, where they were used to purify water and treat diseases [142]. ACs were employed during the first world war as a filter material for gas masks, and they have been developed for a variety of applications in the following century [142, 143]. Graphite has been known as a mineral since the middle ages [137]. In recent years, graphite has been used as a dry lubricant, for electrodes and as heating elements [137]. Graphene, since its isolation, has been investigated for a wide range of applications, such as electrodes [144, 145], gas storage materials, corrosion resistant coatings, gas and biosensors, light bulbs and drug delivery devices, and desalination and separation membranes, to name but a few [141, 144-146].

In 2012, Nair et al. [147] reported that multilayer GO membranes of thickness in the range $0.1-10 \mu \mathrm{m}$, formed by depositing GO flakes of lateral dimensions of a few $\mu \mathrm{m}$, allowed virtually unimpeded evaporation of water, while being impermeable to all other liquids and gases, even helium, in the dry state. They went on to demonstrate that such membranes exhibit molecular sieving of solutes with hydrated diameters greater than $0.9 \mathrm{~nm}$ [148]. Tunable sieving of smaller ions was achieved by orienting GO flakes in the direction of permeation and fixing the spacing by encapsulation with an epoxy resin [149]. Conductive filaments, which can be introduced into GO membranes by controlled electrical breakdown, enable water permeation to be controlled electrically [150]. Ultrathin GO membranes, down to $c a .10 \mathrm{~nm}$ in thickness, show permeation of organic solvents and are potentially useful for organic solvent nanofiltration [151].

Following the first report from Manchester of unimpeded evaporation of water through GO membranes [147], there has been a great deal of research on graphene-based membranes in general, and on hydrophilic pervaporation utilising GO in particular. Yeh et al. [152] coated multilayer GO onto a thin film nanofibrous composite support and used it for ethanol dehydration, reporting a separation factor of 308 and permeate flux of $2.2 \mathrm{~kg} \mathrm{~m}^{-2} \mathrm{~h}^{-1}$ for removal of water from an $80 \mathrm{wt} \%$ ethanol/water mixture, outperforming a commercial membrane. Tang et al. [153] studied ethanol dehydration with free-standing GO membranes. Li et al. [154] prepared membranes of $\mathrm{GO}$ on porous, tubular alumina supports, and obtained good performance for dehydration of ethanol, 1-propanol, 2-propanol, butanol isomers and ethyl acetate. Hung et al. [155] used diamines to crosslink GO and control the interlayer spacing, reporting enhanced performance for ethanol dehydration. Another paper by Hung et al. [156] investigated dehydration of 1-butanol by composite membranes of GO on a polyacrylonitrile (PAN) support. Butanol dehydration was also studied by Chen et al. [157] using GO membranes on anodic aluminium oxide discs, and Tsou et al. [158] with GO membranes on a modified PAN support. Liang et al. [159] explored the potential of pervaporation with GO/PAN composite membranes for desalination. Pervaporation desalination was also investigated by Cheng et al. [160], using membranes of GO on an electrospun nanofibrous PAN support. Ying et al. [161] 
intercalated superhydrophilic metal-organic frameworks into the GO layered structure and reported enhancements in separation factor and flux for pervaporation of an ethyl acetate/water mixture. Qin et al. [162] surface-crosslinked GO with 1,3,5-benzenetricarbonyl trichloride in membranes for ethanol dehydration. Lecaros et al. [163] sought to tune the interlayer spacing in $\mathrm{GO}$ by crosslinking with tiny amounts of poly (vinyl alcohol) and used the membranes for separation of an acetic acid/water mixture. Hua et al. [164] utililsed aldehyde-functionalised GO in membranes for dehydration of ethanol, 2-propanol and 1-butanol. Zhao et al. [165] investigated dehydration of ethanol with membranes in which GO was crosslinked with poly (ethylene glycol) diamines and the GO layer was then coated with a thin film of sodium alginate. Boffa et al. [166] utilised a humic acid-like biopolymer to stabilize GO membranes for ethanol dehydration. Van Gestel and Barthel [167] looked at 2-propanol dehydration with membranes prepared by dip-coating a GO dispersion on a specially prepared ceramic support, followed by thermal treatment at $300{ }^{\circ} \mathrm{C}$ in air. Guan et al. [168] used lignin-based cations to stabilise GO membranes for ethanol dehydration.

GO may be dispersed within a polymeric phase to modify the separation performance. Suhas et al. [169] added GO to sodium alginate nanocomposite membranes and investigated the dehydration of 2-propanol, reporting an improvement in performance for GO loadings up to $2 \mathrm{wt} \%$, but a loss of selectivity at higher loadings. Wang et al. [170] mixed GO quantum dots (lateral size $<100 \mathrm{~nm}$ ) into sodium alginate to form membranes for the dehydration of ethanol. Dharupaneedi et al. [171] dispersed GO in chitosan for pervaporation of ethanol/ water and 2-propanol/water mixtures. Lin et al. [172] investigated $\mathrm{GO} /$ chitosan membranes for pervaporationassisted esterification. GO and $\mathrm{rGO} /$ chitosan membranes were studied by Hung et al. [173] for methanol dehydration. Manshad et al. [174] combined GO with Ultem polyetherimide for 1-butanol dehydration. Salehian and Chung [175] prepared mixed matrix membranes of ammonia-functionalised $\mathrm{GO}$ in a polyimide for 2-propanol dehydration.

Another approach to GO/polymer hybrid membranes was taken by Wang et al. [176], who created polyelectrolyte complexes of poly (acrylic acid) with poly (ethylene imine)-modified GO and investigated the membranes for both nanofiltration and pervaporative dehydration.

While the majority of studies on pervaporation of aqueous mixtures have focused on the removal of water, there is interest in organophilic pervaporation for feeds in which the organic component is present at low concentration. Dizaji et al. [177] created hybrid polydimethylsiloxanegraphene/polyethersulfone membranes, using both rGO and graphene produced by electrochemical exfoliation of graphite, for removal of phenol from water.
GO has been utilised in membranes for organicorganic separations by pervaporation. Wang et al. [178] created "pore-filling" composite membranes with a separation layer of GO in poly (vinyl alcohol) (PVA), both on the surface and in the pores of an asymmetric PAN support, and used them for the separation of a toluene/ heptane mixture, the addition of GO improving the separation of the aromatic component. Khazaei et al. $[179,180]$ studied GO/PVA mixed matrix membranes for the separation of toluene from its mixtures with iso-octane. Maya et al. [181] incorporated reduced graphene oxide (rGO) into polychloroprene membranes for the pervaporation of chloroform/acetone azeotropic liquid mixtures.

\section{Pervaporation with PIM-based membranes}

With a plethora of materials used as membranes for PV purposes, the use of PIMs represents a logical step in the development of high performance PV membranes. Many membranes suffer from a trade-off relationship between flux and selectivity, therefore the use of PIMs was seen as a way to overcome this trade-off by maintaining selectivity whilst increasing permeability through their inherent porosity. In fact the first reported application of PIM-1 was for the PV separation of phenol from aqueous solutions [2]. In subsequent years there has been increasing attention towards the application of PIMs in PV processes.

\section{Self-standing membranes \\ Separation of alcohol/water mixtures}

Investigations of PV utilizing PIMs have largely focused on the separation of alcohols from water. Results for unsupported PIM-1 membranes are summarised in Table 1.

The initial report on PIM-1 as a membrane by Budd et al. [2] tested its ability to remove phenol selectively from water. Phenol removal is of particular interest due to phenolic compounds being present in industrial waste streams. Selectivities and fluxes were obtained that were comparable to those reported for hydrophobic, rubbery PDMS composite membranes [186] ( $\beta=16-18$ for PIM-1 compared to $\beta=18$ for supported PDMS; Flux $=0.20-0.52 \mathrm{~kg} \mathrm{~m}^{-2} \mathrm{~h}^{-1}$ for PIM-1 compared to $0.10-0.25 \mathrm{~kg} \mathrm{~m}^{-2} \mathrm{~h}^{-1}$ for supported PDMS). The similarity is attributed to the inherent microporosity of the glassy PIM-1, allowing it to demonstrate permeation behaviour similar to that of a thin film of a rubbery polymer. The effect of temperature was also investigated, showing increased flux with increased temperature, whilst the separation factor changed little [2]. While the membranes showed an almost tenfold increase of phenol in the permeate compared to the initial feed, there was still room for improvement in terms of both selectivity and flux.

A study by Adymkanov et al. [183] investigated the effect of increasing molecular size on transport through 
Table 1 Pervaporation of alcohols from aqueous solution using self-standing PIM-1 membranes

\begin{tabular}{|c|c|c|c|c|c|}
\hline Alcohol & Conc. (wt\%) & Temp. $\left({ }^{\circ} \mathrm{C}\right)$ & $\beta$ & Normalised flux $\left(\mathrm{kg} \mu \mathrm{m} \mathrm{m}^{-2} \mathrm{~h}^{-1}\right)$ & Ref. \\
\hline Phenol & 5 & 50 & 18 & 8.0 & [2] \\
\hline Phenol & 5 & 60 & 18 & 14.8 & [2] \\
\hline Phenol & 1 & 70 & 16 & 8.4 & [2] \\
\hline Phenol & 3 & 70 & 16 & 11.2 & [2] \\
\hline Phenol & 5 & 70 & 18 & 20.8 & [2] \\
\hline Phenol & 5 & 80 & 18 & 26.8 & [2] \\
\hline Methanol & 1.77 & 30 & 11.1 & 9.4 & [182] \\
\hline Ethanol & 10 & 30 & 11 & 14.6 & [183] \\
\hline Ethanol & 10 & 40 & 10 & 20.1 & [183] \\
\hline Ethanol & 10 & 50 & 9 & 34.2 & [183] \\
\hline Ethanol & 10 & 60 & 9 & 43.3 & [183] \\
\hline Ethanol & 2.52 & 30 & 5.3 & 6.6 & [182] \\
\hline Ethanol & 5 & 50 & 3.7 & 62.7 & [184] \\
\hline Ethanol & 5 & 60 & 3.6 & 65.2 & [184] \\
\hline Ethanol & 9 & 50 & 3.2 & 46.7 & [184] \\
\hline Ethanol & 9 & 60 & 3.3 & 66.4 & [184] \\
\hline Ethanol & 5 & 65 & 3.1 & 5.9 & [185] \\
\hline 2-Propanol & 3.26 & 30 & 2.4 & 3.6 & [182] \\
\hline 1-Butanol & 5 & 65 & 13.5 & 32.4 & [185] \\
\hline
\end{tabular}

PIM-1 membranes. Studies with pure solvents showed that the normalized mass flux decreased in the sequence: Metha-

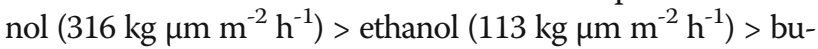

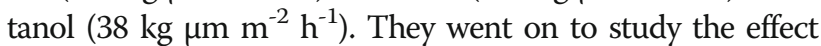
of temperature on the pervaporation of a $10 \%$ solution of ethanol in water, showing an increase in flux with an increase in temperature, with little change in separation factor (Table 1). The flux was comparable to that of the ultra-

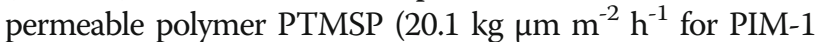
compared to $19-24 \mathrm{~kg} \mu \mathrm{m} \mathrm{m}^{-2} \mathrm{~h}^{-1}$ for PTMSP at $40{ }^{\circ} \mathrm{C}$ ) $[183,187]$. Additionally, they reported no appreciable reduction in flux over time [183]. These results gave industrial relevance to PIM-1 as a PV membrane, as it proved to have high permeabilities for alcohols and remained permeable over extended periods of time. Table 1 includes data from Wu et al. [182] for methanol, ethanol and 2-propanol, and data from Alberto et al. [185] for ethanol and 1-butanol.

The selective removal of 1-butanol from aqueous solution by self-standing PIM-1 membranes was investigated by Žák et al. [188]. Their results were reported in terms of the permeabilities of butanol, $P_{\mathrm{B}}$, and water, $P_{\mathrm{W}}$, with selectivity expressed as $\alpha=P_{\mathrm{B}} / P_{\mathrm{W}}$. They studied the change in performance for an aged sample of pure PIM1. For a 2 wt.\% 1-butanol feed at $50^{\circ} \mathrm{C}$, the freshly cast membrane showed $P_{\mathrm{B}}=9.0 \times 10^{-5} \mathrm{~mol} \mathrm{~m} \mathrm{kPa}^{-1} \mathrm{~h}^{-1}$ with $\alpha=2.8$. After aging for over a year (370 days), $P_{\mathrm{B}}$ had decreased to $1.10 \times 10^{-5} \mathrm{~mol} \mathrm{~m}{ }^{-1} \mathrm{kPa}^{-1} \mathrm{~h}^{-1}$, but the selectivity had increased to 5.1 [188]. They noted that fresh and aged membranes exhibited different dependencies of selectivity on 1-butanol concentration. Further work is required to understand and control ageing effects under the conditions of pervaporation.

Experimental studies of pervaporation of alcohol/water mixtures with PIM-1 membranes have focused on relatively low alcohol concentrations appropriate, for example, for the recovery of bioethanol or biobutanol from fermentation broths. An atomistic computer simulation study by Shi et al. [189] considered the situation of an ethanol/water azeotrope (95.5 wt\% ethanol). They suggested that under these conditions PIM-1 membranes should show good selectivity for water. However, this has not been tested in the laboratory.

\section{Separation of volatile organic compounds from aqueous solution}

Wu et al. [182], in addition to the data for methanol, ethanol and 2-propanol given in Table 1, provided results for the pervaporative removal of a variety of volatile organic compounds from aqueous solution, as presented in Table 2 . Their research showed particularly high separation factors and fluxes for ethyl acetate, diethyl ether and acetonitrile. It was also noted that less flexible ring compounds such as tetrahydrofuran and dioxane exhibited poorer performance, which they attributed to differences in their shape and size which 
Table 2 Pervaporation of volatile organic compounds from aqueous solution using self-standing PIM-1 membranes

\begin{tabular}{|c|c|c|c|c|c|}
\hline Organic compound & Conc. (wt\%) & Temp. $\left({ }^{\circ} \mathrm{C}\right)$ & $\beta$ & Normalised flux $\left(\mathrm{kg} \mu \mathrm{m} \mathrm{m}^{-2} \mathrm{~h}^{-1}\right)$ & Ref. \\
\hline Diethyl ether & 3.99 & 30 & 176 & 33.1 & [182] \\
\hline Ethyl acetate & 4.71 & 30 & 19.2 & 39.5 & [182] \\
\hline Tetrahydrofuran & 3.89 & 30 & 16.5 & 7.02 & [182] \\
\hline Acetone & 3.16 & 30 & 20.9 & 17.8 & [182] \\
\hline Dioxane & 4.71 & 30 & 0.93 & 1.94 & [182] \\
\hline Acetonitrile & 2.25 & 30 & 39.6 & 20.7 & [182] \\
\hline Acetic acid & 3.26 & 30 & 6.14 & 3.42 & [182] \\
\hline
\end{tabular}

meant they were unable to pass through the smaller pores in the membrane.

\section{Separation of water/ethylene glycol and methanol/ethylene glycol mixtures}

A second study by Wu et al. [190] focused on the purification of ethylene glycol (EG) from both water and methanol mixtures (Table 3). The overall aim was to develop a high throughput, highly selective membrane to outperform current distillation techniques used for the industrial purification of ethylene glycol. The separation of water from ethylene glycol showed increases in both the flux and separation factor with increasing water content. The hydrophobic nature of PIM-1 means that the degree of swelling decreases with increasing water content in the feed. Therefore, it is concluded that the separation process is dominated by the diffusion process, with the water molecules having a greater advantage in diffusing through the membrane owing to their smaller size compared to the ethylene glycol molecules. An increase in both flux and separation factor was observed with an increase in temperature, as expected. For methanol/ethylene glycol mixtures there was also an increase in both flux and separation factor with increase in its content. The fluxes proved to be much greater than those observed with water. However, while there was still an increase in flux with an increase in temperature, there was a reduction in separation factor. This difference in performance between water/ethylene glycol and methanol/ethylene glycol was caused by the difference in activation energies between components in each of the mixtures being studied.

Further work by Chen et al. [191] sought to improve the separation of water/ethylene glycol mixtures by making the membrane more hydrophilic. This was achieved using base hydrolysed PIM-1 membranes, with the aim of converting nitrile groups in PIM-1 into carboxylate groups [192]. The carboxylated PIM-1 (cPIM-1) membranes showed higher fluxes and separation factors than unmodified PIM-1 (Table 3). The use of hydrolysed

Table 3 Pervaporation of water and methanol from ethylene glycol using self-standing PIM-1 or carboxylated PIM-1 (cPIM-1) membranes. For CPIM-1 membranes the reported degree of carboxylation is indicated in parentheses

\begin{tabular}{|c|c|c|c|c|c|c|}
\hline Impurity & Conc. (wt\%) & Temp. $\left({ }^{\circ} \mathrm{C}\right)$ & Membrane & $\beta$ & 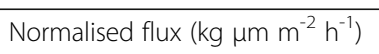 & Ref. \\
\hline Water & 18.50 & 20 & PIM-1 & 18.8 & 1.25 & [190] \\
\hline Water & 6.56 & 30 & PIM-1 & 36.4 & 0.82 & [190] \\
\hline Water & 18.50 & 30 & PIM-1 & 42.9 & 2.87 & [190] \\
\hline Water & 22.66 & 30 & PIM-1 & 51.1 & 3.82 & [190] \\
\hline Water & 18.50 & 40 & PIM-1 & 47.3 & 3.53 & [190] \\
\hline Water & 18.50 & 50 & PIM-1 & 64.5 & 6.91 & [190] \\
\hline Water & 10 & 30 & CPIM-1(0.69) & 92.3 & 8.41 & [191] \\
\hline Water & 20 & 30 & CPIM-1(0.69) & 69.0 & 11.7 & [191] \\
\hline Water & 20 & 30 & CPIM-1(0.94) & 75.9 & 13.7 & [191] \\
\hline Methanol & 18.50 & 20 & PIM-1 & 30.5 & 5.19 & [190] \\
\hline Methanol & 8.15 & 30 & PIM-1 & 7.15 & 4.92 & [190] \\
\hline Methanol & 18.50 & 30 & PIM-1 & 24.2 & 10.4 & [190] \\
\hline Methanol & 23.16 & 30 & PIM-1 & 26.2 & 14.7 & [190] \\
\hline Methanol & 18.50 & 40 & PIM-1 & 14.6 & 13.4 & [190] \\
\hline Methanol & 18.50 & 50 & PIM-1 & 6.15 & 23.9 & [190] \\
\hline
\end{tabular}


PIM-1 membranes therefore has a great deal of potential for applications in the industrial dehydration of organic solvents [192-195].

\section{Separation of organic/organic mixtures}

The potential of PIM-based membranes for organic/organic separations is as yet little explored. Wu et al. [190] looked at methanol/ethylene glycol mixtures, as discussed above. Cihal et al. [196] have investigated the separation of the "green" reagent dimethyl carbonate (DMC) from its mixtures with methanol, comparing PIM-1 with the rubbery polymer PDMS and the high free volume glassy polymer PTMSP. For pervaporation of the DMC/methanol azeotrope ( $82 \mathrm{~mol} \%$ methanol) at $40^{\circ} \mathrm{C}$, a PIM-1 membrane achieved a separation factor of 2.3. A PDMS membrane showed similar separation with lower flux, while PTMSP showed virtually no separation. They also compared pervaporation with vapour permeation through PIM-1 membranes, the latter process giving higher separation factors (up to 5.1) for the azeotropic mixture, at the expense of a reduction in flux. For feeds rich in DMC (>60 mol\% DMC) there was a loss of separation in pervaporation mode, attributed to a loss of sorption selectivity because sorbed DMC solubilises methanol in the membrane. However, there was no loss of separation in vapour permeation mode, separation factors up to 6.5 being achieved for feeds that were diluted with an inert gas. It is worth noting that vapour permeation should be considered as an alternative to pervaporation when assessing membranes for the separation of volatile liquid mixtures.

\section{Polymer blend membranes}

A PIM may be blended with other polymers to improve the separation performance. Salehian et al. [197] prepared blend membranes of the polyimide P84 with hydrolysed PIM-1 (cPIM-1), aiming to combine the high permeability of cPIM-1 with the high selectivity of P84 in the dehydration of 2-propanol. Pervaporation experiments at $60^{\circ} \mathrm{C}$ on a 2-propanol/water mixture $(85 / 15$ $\mathrm{wt} \%)$ showed that incorporation of $10 \mathrm{wt} \% \mathrm{cPIM}-1$ into a P84 membrane improved the water permeability by $87 \%$, whilst the high selectivity observed with pure P84 was maintained.

A further study by Yong et al. [195] investigated the effects of blending cPIM-1 with three polymers (Matrimid polyimide, Torlon polyamide-imide and P84 polyimide) on the dehydration pervaporation of three alcohols (ethanol, 2-propanol and 1-butanol). Results are given in Table 4 for membranes with 20 wt\% cPIM-1, at which loading there was generally a significant increase in flux without too great a loss of selectivity. Data for 0,10 and $30 \mathrm{wt} \%$ cPIM-1 are to be found in the reference. With all three polymers, very high separation factors were observed for 1-butanol dehydration at cPIM-1 loadings up to $20 \mathrm{wt} \%$, but at higher loading, although the flux increased, there was a substantial drop in selectivity.

While polymer blends with cPIM-1 can be used to tailor the performance of hydrophilic membranes for alcohol dehydration at low water content, PIM-1 itself may be used to tailor the performance of organophilic membranes for the recovery of alcohols from aqueous solution at low alcohol concentration. It is much harder to achieve high selectivity for alcohol recovery than for dehydration, as the selectivity is dominated by sorption of the alcohol, but once alcohol is sorbed in the membrane it solubilises water in the membrane. Zhang et al. [198] have developed a procedure for creating hybrid membranes of PIM-1 in crosslinked PDMS. For the pervaporation separation at $60{ }^{\circ} \mathrm{C}$ of 1-butanol from water at the very low alcohol concentration of $1 \mathrm{wt} \%$, for a membrane with $8 \mathrm{wt} \%$ loading of PIM-1 in PDMS, they achieved a separation factor of 30.7 with a normalised total flux of $31.4 \mathrm{~kg} \mu \mathrm{m} \mathrm{m}^{-2} \mathrm{~h}^{-1}$. The membrane showed stable performance over $240 \mathrm{~h}$ continuous operation.

\section{Mixed matrix membranes}

PIM-1 membranes with filler particles dispersed throughout to form mixed matrix membranes (MMMs) have been

Table 4 Dehydration pervaporation of alcohol/water mixtures ( $85 \mathrm{wt} \%$ alcohol) at a temperature of $60^{\circ} \mathrm{C}$ using blend membranes of polyimides with 20 wt\% hydrolysed PIM-1 (CPIM-1)

\begin{tabular}{lllll}
\hline Alcohol & Blended polymer & $\beta$ & Normalised flux $\left(\mathrm{kg} \mu \mathrm{m} \mathrm{m}^{-2} \mathrm{~h}^{-1}\right)$ & 4.92 \\
\hline Ethanol & Matrimid & 340 & 0.85 & Ref. \\
Ethanol & Torlon & 157 & 1.9 & [195] \\
Ethanol & P84 & 199 & 2.0 \\
2-Propanol & Matrimid & 780 & 1.2 \\
2-Propanol & Torlon & 719 & 2.1 \\
2-Propanol & P84 & 72 & 2.4 \\
1-Butanol & Matrimid & $>5000$ & 1.0 \\
1-Butanol & Torlon & $>5000$ & [195] \\
1.Butanol & P84 & $>5000$ & [195] \\
\hline
\end{tabular}


studied for the separation of alcohol/water mixtures. Fillers that have been investigated include silicalite, as an example of a porous filler, and graphene oxide, as an example of a non-porous, high surface area 2D material. In each case, the filler has been functionalised to improve compatibility with the polymer phase. Representative results are given in Table 5.

Initial work on PIM-based MMMs for PV by Mason et al. [184] used as a filler the hydrophobic zeolite silicalite-1, functionalized on the outer surface with $-\left(\mathrm{CH}_{2}\right)_{2} \mathrm{Ph}$ groups. Results for the pervaporation of ethanol from aqueous solution (5 and 9 wt\% ethanol) at three filler loadings and temperatures of 50 and $60^{\circ} \mathrm{C}$ are given in Table 5. Data for other temperatures can be found in the reference. MMMs with filler loadings of $28 \mathrm{wt} \%$ or higher showed increases in separation factor compared to pure PIM-1 membranes (Table 1) studied under the same conditions. The addition of a porous filler serves both to increase the free volume in the dry membrane and to reduce the swelling when used for pervaporation of ethanol/water mixtures.

The archetypal 2D material, graphene, is an effective barrier to molecular transport and when incorporated into a polymer at high loading it can greatly reduce permeability. However, at low loading it may tailor the separation performance of a membrane in various ways. Firstly, its high surface area provides sorption sites that modify the sorption selectivity of the membrane. Secondly, permeating molecules have to diffuse around the graphene flakes and the tortuous diffusion path influences the diffusion selectivity. Thirdly, the presence of flakes with lateral dimensions that are large relative to the molecular scale can help to control swelling and ageing. Fourthly, the large area of graphene surface restricts the conformational freedom of polymer chains in its vicinity, frustrating their ability to pack together, and thus increasing free volume and enhancing permeability;

Table 5 Pervaporation of alcohols from aqueous solution using mixed matrix PIM-1 membranes. Fillers: $M F /$ silicalite-1 (CH $)_{2} \mathrm{Ph}, \mathrm{GO}-$ ODA octadecyl-functionalised graphene oxide, rGO-ODA reduced octadecyl-functionalised graphene oxide, rGO-OA reduced octylfunctionalised graphene oxide

\begin{tabular}{|c|c|c|c|c|c|c|c|}
\hline Alcohol & Conc. (wt\%) & Filler & Loading (wt\%) & Temp. $\left({ }^{\circ} \mathrm{C}\right)$ & $\beta$ & Normalised flux $\left(\mathrm{kg} \mu \mathrm{m} \mathrm{m}^{-2} \mathrm{~h}^{-1}\right)$ & Ref. \\
\hline Ethanol & 5 & $\mathrm{MFI}$ & 13 & 50 & 3.7 & 27.7 & [184] \\
\hline Ethanol & 5 & $\mathrm{MFI}$ & 13 & 60 & 3.3 & 29.6 & [184] \\
\hline Ethanol & 5 & $\mathrm{MFI}$ & 28 & 50 & 4.9 & 36.7 & [184] \\
\hline Ethanol & 5 & $\mathrm{MFI}$ & 28 & 60 & 5.7 & 54.6 & [184] \\
\hline Ethanol & 9 & $\mathrm{MFI}$ & 28 & 50 & 3.7 & 80.5 & [184] \\
\hline Ethanol & 9 & $\mathrm{MFI}$ & 28 & 60 & 5.1 & 50.3 & [184] \\
\hline Ethanol & 9 & $\mathrm{MFI}$ & 47 & 50 & 4.7 & 18.6 & [184] \\
\hline Ethanol & 9 & $\mathrm{MFI}$ & 47 & 60 & 4.3 & 22 & [184] \\
\hline Ethanol & 5 & GO-ODA & 0.01 & 65 & 1.1 & 3.1 & [185] \\
\hline Ethanol & 5 & GO-ODA & 0.1 & 65 & 3.1 & 5.5 & [185] \\
\hline Ethanol & 5 & GO-ODA & 0.5 & 65 & 2.1 & 3.8 & [185] \\
\hline Ethanol & 5 & rGO-ODA & 0.01 & 65 & 3.0 & 3.7 & [185] \\
\hline Ethanol & 5 & rGO-ODA & 0.1 & 65 & 2.0 & 3.2 & [185] \\
\hline Ethanol & 5 & rGO-ODA & 0.5 & 65 & 1.5 & 5.0 & [185] \\
\hline Ethanol & 5 & rGO-OA & 0.01 & 65 & 1.8 & 3.8 & [185] \\
\hline Ethanol & 5 & rGO-OA & 0.1 & 65 & 5.1 & 9.5 & [185] \\
\hline Ethanol & 5 & rGO-OA & 0.5 & 65 & 2.9 & 6.8 & [185] \\
\hline 1-Butanol & 5 & GO-ODA & 0.01 & 65 & 12.2 & 17.1 & [185] \\
\hline 1-Butanol & 5 & GO-ODA & 0.1 & 65 & 16.1 & 30.0 & [185] \\
\hline 1-Butanol & 5 & GO-ODA & 0.5 & 65 & 17.4 & 22.2 & [185] \\
\hline 1-Butanol & 5 & rGO-ODA & 0.01 & 65 & 21.5 & 34.5 & [185] \\
\hline 1-Butanol & 5 & rGO-ODA & 0.1 & 65 & 26.9 & 23.0 & [185] \\
\hline 1-Butanol & 5 & rGO-ODA & 0.5 & 65 & 17.6 & 30.8 & [185] \\
\hline 1-Butanol & 5 & rGO-OA & 0.01 & 65 & 22.6 & 43.9 & [185] \\
\hline 1-Butanol & 5 & rGO-OA & 0.1 & 65 & 32.9 & 27.6 & [185] \\
\hline 1-Butanol & 5 & rGO-OA & 0.5 & 65 & 27.1 & 35.1 & [185] \\
\hline
\end{tabular}


this can be particularly significant for gas separations [199], but may be less important for liquid separations where the polymer is swollen with the permeating species. Fifthly, interfacial defects or voids may provide rapid diffusion paths. It must be emphasised that with a 2D material these effects may be seen at loadings much lower than are normally used for particulate fillers.

PIM-1 can interact with graphene sheets [200], which serves to stabilise graphene dispersions. PIM-1/graphene composites have been prepared and the gas permeation behaviour studied [199]. However, there is a tendency for graphene sheets to re-agglomerate during membrane formation [201]. Therefore, studies of pervaporation have made use of graphene-based fillers functionalised with alkyl chains to improve compatibility and discourage reagglomeration. The alkyl chains may also influence the sorption selectivity of the membrane. Graphene oxide (GO) provides a convenient starting point for functionalisation, and can be reduced to a graphene-like material.

Alberto et al. [185] prepared GO by a modified Hummers' method, oxidising graphite with $\mathrm{KMnO}_{4}$ in a solution of $\mathrm{KNO}_{3}$ in $\mathrm{H}_{2} \mathrm{SO}_{4}$, followed by a mixture of $\mathrm{H}_{2} \mathrm{O}_{2}$ and $\mathrm{H}_{2} \mathrm{SO}_{4}$. This introduces various oxygen-containing functional groups (hydroxyl, epoxide, carboxylic acid) and enables the material to be dispersed in water. The GO was then functionalised with alkyl chains by reaction with alkylamines, octadecylamine yielding a material with long chains (18 carbons), termed GO-ODA, and octylamine yielding a material with shorter chains (8 carbons), termed GO-OA. Chemical reduction was subsequently carried out with hydrazine monohydrate to give rGO-ODA and rGO-OA. The process is illustrated in Fig. 3.

GO-ODA, rGO-ODA and rGO-OA could be dispersed in chloroform, a solvent for PIM-1, and so were used to prepare MMMs with PIM-1. Results are given in Table 5 for pervaporation of ethanol and 1-butanol from aqueous solution with membranes incorporating $0.01,0.1$ and $0.5 \mathrm{wt} \%$ filler. Data for a higher filler loading can be found in the reference [185]. For ethanol pervaporation, under the conditions employed, the addition of GOODA or rGO-ODA showed no advantage compared to PIM-1 alone (Table 1), but rGO-OA gave a modest improvement in separation factor and flux at a loading of $0.1 \mathrm{wt} \%$ (Table 5). More impressive improvements were achieved for 1-butanol pervaporation, rGO-OA at 0.1 wt\% giving a separation factor more than twice that for PIM-1 alone. This illustrates the potential for high surface area 2D fillers to improve the overall performance of PIM membranes for butanol recovery.

\section{Thin film composite membranes}

To improve the overall flux through PIM-1 membranes, thin film composite (TFC) membranes have been prepared with a PIM-1 separation layer on a porous support, both with and without fillers being added to the separation layer. The TFC membranes have been investigated for pervaporation of 1-butanol/water mixtures (Table 6). Whereas Tables 1, 2, 3, 4, 5 have given a normalised flux, to enable better comparison of materials, Table 6 gives the total flux and PSI as an indication of membrane performance.

\section{Pure PIM-1 selective layer}

Gao et al. [202] investigated TFC membranes comprising PIM-1 separation layers on PVDF supports. The hydrophobic polymer PVDF was chosen as previous work with PIM-1 coated on more hydrophilic PAN supports had given poor results for PV. A range of asymmetric PVDF supports were prepared by casting PVDF dope solutions onto polypropylene non-woven fabric, followed by immersion in distilled water. The pore size and surface porosity of the support was controlled by varying the PVDF concentration in the dope solution and through the use of phosphoric acid as a non-solvent additive. Pore sizes at the support surface were in the range $25-55 \mathrm{~nm}$ and fractional surface porosities were in the range $0.38-0.69$. High surface porosity of the support was shown to be particularly important for achieving high flux TFC membranes. For a given support, the total flux obtained for TFC membranes was shown to increase on decreasing the thickness of the PIM-1 layer from $c a .3 \mu \mathrm{m}$ to $c a .1 \mu \mathrm{m}$. However, the benefit of reducing the thickness of the separation layer was partially offset by a decrease in the thickness-normalised flux. The reduction in the apparent permeability of the PIM-1 layer at small thicknesses may arise from effects related to the process (concentration polarization can be pronounced for thin films that exhibit high fluxes) and/or effects related to the material (polymer packing is different in a thin film, close to a surface, than in bulk polymer). One set of data for a PIM-1 TFC membrane is included in Table 6, demonstrating a combination of flux and selectivity that outperforms the vast majority of membranes reported in the literature [202]. Data for other membranes and temperatures are presented in the reference [202].

\section{Mixed matrix selective layer}

Lan et al. [203] investigated the use of fillers in PIM-1 membranes for PV separations of 1-butanol from water, through the addition of fumed silica nanoparticles modified with the silane coupling agent 3-methacryloxypropyltrimethoxysilane to aid dispersion. Solutions of PIM-1 with various loadings of the modified nano-fumed silica (MNFS) were cast onto a cellulose acetate (CA) microfiltration membrane as a support. The CA membrane was saturated with water prior to casting the PIM-1 layer, so that the separation layer did not penetrate into the pores of the support. Increasing the amount of MNFS, up to $4 \mathrm{wt} \%$ loading, led to a decrease in 


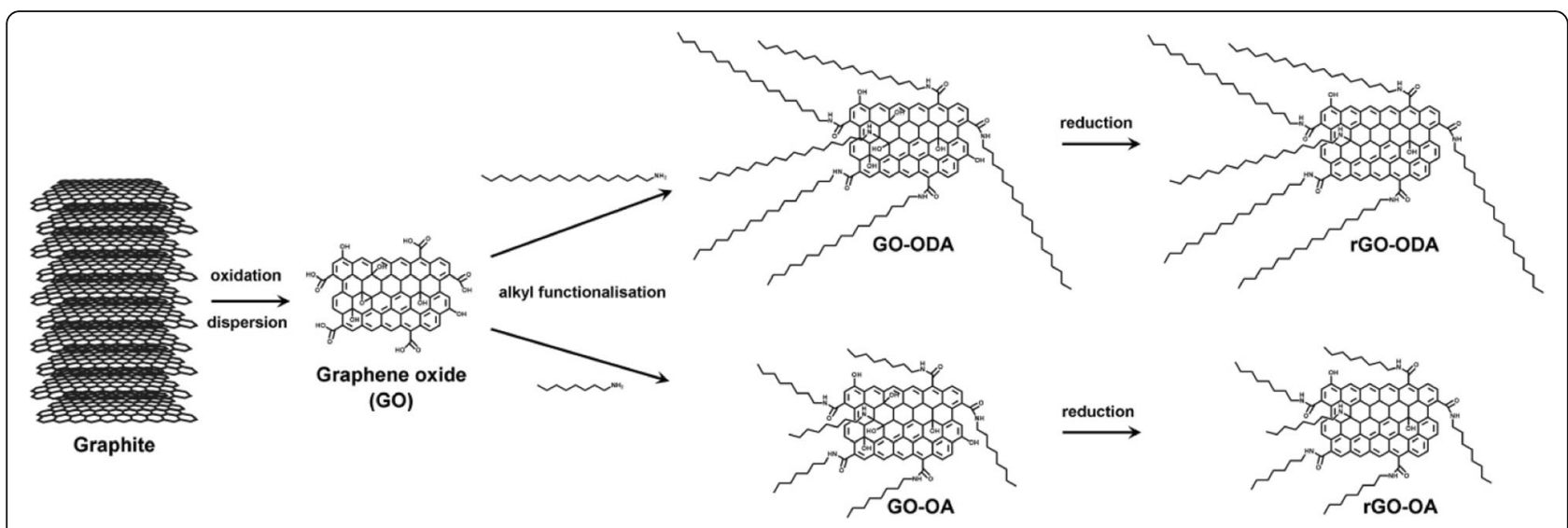

Fig. 3 Preparation of alkyl-functionalised graphene-like fillers

the degree of swelling in $5 \mathrm{wt} \%$ 1-butanol aqueous solution at $20^{\circ} \mathrm{C}$, and a concomitant increase in PV separation factor. PV results for $4 \mathrm{wt} \%$ loading are given in Table 6. Data for other loadings and temperatures are presented in the reference [203].

Carbon black functionalised with the silane coupling agent aminopropyltriethoxysilane (APTS-CB) was also investigated as a filler for PIM-1 TFC membranes on CA supports by Lan et al. [204]. In pervaporation of 5 wt\% 1-butanol aqueous solution at $30^{\circ} \mathrm{C}$, increases in both selectivity and flux were observed with APTS-CB loadings up to $4 \mathrm{wt} \%$. The best results are given in Table 6. On increasing the loading further to $6 \mathrm{wt} \%$ there was a decrease in separation factor, attributed to aggregation of filler particles creating voids at the filler/ particle interface that allow rapid water transport. Separation factor also decreased on raising the temperature or increasing the butanol concentration in the feed.

The work discussed previously on mixed matrix membranes of alkyl-functionalised GO and reduced GO with
PIM-1 [185], and on TFC membranes of PIM-1 on PVDF supports [202], was extended by Alberto et al. [205] to the development of thin film nanocomposite (TFN) membranes with a mixed matrix selective layer of PIM-1 with graphene-like fillers, on a PVDF support. When incorporating 2D materials into a film with a thickness of the order a micron, the lateral size of the flakes is critical. They investigated flakes with lateral size in the micrometre range of octadecyl-functionalised graphene oxide before and after reduction, and of octylfunctionalised reduced graphene oxide, designated GOODA-B, rGO-ODA-B and rGO-OA-B, respectively, and the corresponding materials with flakes with lateral size of the order of $250 \mathrm{~nm}$, designated GO-ODA-S, rGOODA-S and rGO-OA-S. For pervaporation of $5 \mathrm{wt} \%$ 1butanol aqueous solution at $65^{\circ} \mathrm{C}$, the addition of the larger flakes led to a reduction in separation factor, attributed to voids associated with the polymer/filler interface or with agglomerates of the filler. In contrast, addition of the smaller flakes at loadings up to $0.1 \mathrm{wt} \%$ generally

Table 6 Pervaporation of 1-butanol from aqueous solution (5 wt.\% 1-butanol) using TFC membranes with a PIM-1 separation layer on poly(vinylidene fluoride) (PVDF) or cellulose acetate (CA) porous supports. Fillers added to the PIM-1 separation layer are modified fumed silica nanoparticles (MNFS), modified carbon black nanoparticles (APTS-CB), small (lateral size in nm range) flakes of octadecyl-functionalised graphene oxide before (GO-ODA-S) and after (rGO-ODA-S) reduction and small flakes of octyl-functionalised reduced graphene oxide (rGO-OA-S)

\begin{tabular}{|c|c|c|c|c|c|c|c|c|}
\hline Filler & Loading (wt\%) & Thickness $(\mu \mathrm{m})$ & Support & Temp. $\left({ }^{\circ} \mathrm{C}\right)$ & $\beta$ & Total flux $\left(\mathrm{kg} \mathrm{m}^{-2} \mathrm{~h}^{-1}\right)$ & PSI $\left(\mathrm{kg} \mathrm{m}^{-2} \mathrm{~h}^{-1}\right)$ & Ref. \\
\hline [PIM-1] & - & 1 & PVDF & 65 & 13.3 & 9.1 & 112 & [202] \\
\hline$[\mathrm{PIM}-1]$ & - & - & $C A$ & 20 & 6.3 & 0.54 & 2.9 & [203] \\
\hline MNFS & 4 & ca. 10 & $C A$ & 20 & 15.5 & 0.51 & 7.4 & [203] \\
\hline [PIM-1] & - & - & $C A$ & 30 & 12.1 & 0.91 & 10 & [204] \\
\hline APTS-CB & 4 & ca. 20 & $C A$ & 30 & 19.7 & 1.12 & 21 & [204] \\
\hline$[\mathrm{PIM}-1]$ & - & $1-1.5$ & PVDF & 65 & 13 & 4.3 & 52 & [205] \\
\hline GO-ODA-S & 0.05 & $1-1.5$ & PVDF & 65 & 15 & 5.7 & 80 & [205] \\
\hline rGO-ODA-S & 0.05 & $1-1.5$ & PVDF & 65 & 14 & 4.6 & 60 & [205] \\
\hline rGO-OA-S & 0.05 & $1-1.5$ & PVDF & 65 & 17 & 5.6 & 90 & [205] \\
\hline
\end{tabular}


led to an improvement in performance, compared to a pure PIM-1 TFC prepared on the same support and analysed under the same conditions. Representative data are given in Table 6. This work demonstrates that $2 \mathrm{D}$ materials are useful for enhancing the separation performance of pervaporation membranes, but that the lateral size needs to be carefully tailored when they are to be incorporated into thin films. It should also be noted that in thin film composite membranes the nature of the support has a major influence on the performance achieved [202].

\section{Concluding remarks}

Pervaporation is becoming an ever more important and viable separation process, as a greener alternative to energyintensive distillation techniques prevalent throughout industry. The use of PIMs for PV separations has seen increased interest in recent years. Competitive performances can be achieved compared to other highly permeable materials such as PDMS and PTMSP. The inherent porosity of a PIM enables high flux to be achieved, while the selectivity can be tailored through chemical modification, through blending with other polymers, or through the addition of fillers such as graphene. For thin film composite membranes, which offer exceptional flux, both the nature of the support, and the size of any filler particles that are added, need to be carefully optimised. A potential problem for use with some solvents is excessive swelling, or even dissolution of the PIM, and strategies for crosslinking the polymer are needed to counter this. One method of effectively crosslinking PIM-1, that has been employed for nanofiltration membranes, involves blending with polyethyleneimine followed by thermal treatment [206], but this may reduce the hydrophobicity of the membrane.

Research on PIMs for PV has so far focused on PIM-1, mainly for organophilic pervaporation, and on its hydrolysed form (cPIM-1) for hydrophilic pervaporation. A wide range of other chemical modifications of PIM-1, of PIM copolymers, and of other PIM structures that have been investigated for gas separations and other applications, have yet to be explored for PV. There is considerable scope to develop new PIM-based membranes tailored for the separation of specific organic/aqueous or organic/organic mixtures.

The addition of small amounts of graphene-based filler to a PIM can enhance PV sorption selectivity and hence tailor membrane performance, as well as potentially helping to control swelling and ageing effects. Future research will see the scope extended to other 2D materials, such as hexagonal boron nitride, transition metal dichalcogenides like $\mathrm{MoS}_{2}$, layered double hydroxides and metal-organic framework nanosheets, that are already being explored in other contexts [207]. The wealth of new materials arising from recent research offers the promise of bespoke membranes for challenging pervaporative separations.

\section{Abbreviations}

AC: Activated carbon; APTS-CB: Carbon black functionalised with aminopropyltriethoxysilane; CA: Cellulose acetate; CPIM-1: Hydrolysed (carboxylated) PIM-1; DMC: Dimethyl carbonate; GO: Graphene oxide; GOODA: Octadecyl-functionalised GO; MMM: Mixed matrix membrane; MNFS: Modified nano-fumed silica; PAN: Polyacrylonitrile;

PDMS: Polydimethylsiloxane; PEBA: Poly(ether-block-amide); PIM: Polymer of intrinsic microporosity; PIM-1: PIM prepared from SBI and TFTPN; PIMPI: Polyimide-PIM; PSI: Pervaporation separation index; PTMSP: Poly[1(trimethylsilyl)-1-propyne]; PV: Pervaporation; PVA: Poly(vinyl alcohol); PVDF: Polyvinylidene fluoride; rGO: Reduced graphene oxide; rGOODA: Reduced octadecyl-functionalised GO; rGO-OA: Reduced octylfunctionalised GO; SBI: 5,5',6,6'-Tetrahydroxy-3,3,3',3'-tetramethyl-1,1'spirobisindane; TB: Tröger's Base; TFC: Thin film composite; TFN: Thin film nanocomposite; TFTPN: Tetrafluoroterephthalonitrile; VOC: Volatile organic compound

\section{Acknowledgements}

Not applicable.

\section{Authors' contributions}

RAK wrote the first draft of the manuscript, which was revised by MP and AV and finalised by PMB. All authors approved the final manuscript.

\section{Authors' information}

PMB is a Professor of Polymer Chemistry at the University of Manchester and is co-inventor of "Polymers of Intrinsic Microporosity". RAK is a postdoctoral research associate at the University of Manchester. AV is Deputy Director of the A.V. Topchiev Institute of Petrochemical Synthesis, Russian Academy of Sciences, where MP is a junior researcher.

\section{Funding}

This work was supported by an Institutional Links grant No. 351983438. The grant is funded by the British Council and by the Ministry of Science and Higher Education of The Russian Federation, project 14.616.21.0100 "Development of a membrane method for the recovery of aromatic hydrocarbons from their mixtures with polar solvents" (project identifier RFMEFI61618X0100).

Availability of data and materials

Data are provided in the manuscript or are available from the references cited.

\section{Competing interests}

The authors declare that they have no competing interests.

\section{Author details}

${ }^{1}$ School of Chemistry, University of Manchester, Manchester M13 9PL, UK. ${ }^{2}$ A.V.Topchiev Institute of Petrochemical Synthesis RAS, Moscow 119991, Russia.

Received: 1 May 2019 Accepted: 25 June 2019

Published online: 08 August 2019

\section{References}

1. Budd PM, Ghanem BS, Makhseed S, McKeown NB, Msayib KJ, Tattershall CE. Polymers of intrinsic microporosity (PIMs): robust, solution-processable, organic nanoporous materials. Chem Commun. 2004:230-1.

2. Budd PM, Elabas ES, Ghanem BS, Makhseed S, McKeown NB, Msayib KJ, Tattershall CE, Wang D. Solution-Processed, Organophilic Membrane Derived from a Polymer of Intrinsic Microporosity. Adv Mater. 2004;16:456-9.

3. Novoselov KS, Geim AK, Morozov SV, Jiang D, Zhang Y, Dubonos SV, Grigorieva IV, Firsov AA. Electric field effect in atomically thin carbon films. Science. 2004;306:666-9.

4. Kober PA. Pervaporation, perstillation and percrystallization. J Amer Chem Soc. 1917;39:944-8.

5. Van der Bruggen B. Pervaporation (PV). In: Encyclopedia of Membranes. Berlin: Springer; 2016.

6. Galiano F, Falbo F, Figoli A. Polymeric Pervaporation Membranes: OrganicOrganic Separations. In: Visakh PM, Nazarenko O, editors. Nanostructured Polymer Membranes, vol. 2. Beverly: Scrivener Publishing; 2016. 
7. Baker RW, Wijmans JG, Huang Y. Permeability, permeance and selectivity: A preferred way of reporting pervaporation performance data. J Membr Sci. 2010;348:346-52.

8. Wijmans JG. Process performance $=$ membrane properties + operating conditions. J Membr Sci. 2003;220:1-3.

9. Boeddeker KW. Terminology in pervaporation. J Membr Sci. 1990;51:259-72.

10. Ten PK, Field RW. Organophilic pervaporation: an engineering science analysis of component transport and the classification of behavior with reference to the effect of permeate pressure. Chem Eng Sci. 2000;55:1425-45.

11. Ong YK, Shi GM, Le NL, Tang YP, Zuo J, Nunes SP, Chung T-S. Recent membrane development for pervaporation processes. Progr Polym Sci. 2016;57:1-31.

12. Binning RC, James FE. Permeation: a new way to separate mixtures. Oil Gas J. 1958:56:104-5.

13. Binning RC, Lee $R$, Jennings JF, Martin EC. Separation of Liquid Mixtures by Permeation. Ind Eng Chem. 1961;53:45-50.

14. Binning RC, Jennings JF, Martin EC. Process for Removing Water from Organic Chemicals. US Patent 3035060; 1962.

15. Loeb S. High Flow Porous Membranes for Separating Water from Saline Solutions. US Patent 3133132;1964.

16. Roy S, Singha NR. Polymeric Nanocomposite Membranes for Next Generation Pervaporation Process: Strategies, Challenges and Future Prospects. Membranes. 2017;7(Article 53):64.

17. Tusel GF, Brüschke HEA. Use of Pervaporation Systems in the Chemical Industry. Desalination. 1985;53:327-38.

18. Rautenbach R, Albrecht R. Separation of Organic Binary Mixtures by Pervaporation. J Membr Sci. 1980;7:203-23.

19. Pribic P, Roza M, Zuber L. How to Improve the Energy Savings in Distillation and Hybrid Distillation-Pervaporation Systems. Sep Sci Tech. 2006:41:2581602.

20. Néel J. Fundamentals of Pervaporation for Ethanol/Water Separation. In: Howell JA, editor. The Membrane Alternative: Energy Implications for Industry. London: Elsevier Applied Science; 1990. p. 59.

21. Liang CZ, Liu JT, Lai J-Y, Chung T-S. High-performance multiple-layer PIM composite hollow fiber membranes for gas separation. J Membr Sci. 2018; 563:93-106.

22. Jue ML, Breedveld V, Lively RP. Defect-free PIM-1 hollow fiber membranes. J Membr Sci. 2017:530:33-41.

23. Aptel P, Challard N, Cuny J, Néel J. Application of the pervaporation process to separate azeotropic mixtures. J Membr Sci. 1976;1:271-87.

24. Binning RC, Lee RJ. Separation of azeotropic mixtures. US Patent 2953502; 1960.

25. Carter JW, Jagannadhaswamy B. Separation of organic liquids by selective permeation through polymeric films. Brit Chem Eng. 1964;9:523.

26. Smitha B, Suhanya D, Sridhar S, Ramakrishna M. Separation of organicorganic mixtures by pervaporation- a review. J Membr Sci. 2004;241:1-21.

27. Ulbricht M, Schwarz H. Novel high performance photo-graft composite membranes for the separation of organic liquids by pervaporation. J Membr Sci. 1997:136:25-33.

28. Park HC, Meertens RM, Mulder MHV, Smoulders CA. Pervaporation of alcohol-toluene mixtures through polymer blend membranes of poly(acrylic acid) and poly(vinyl alcohol). J Membr Sci. 1994;90:265-75.

29. Mandal S, Pangarkar VG. Separation of methanol-benzene and methanoltoluene mixture by pervaporation: effects of thermodynamics and structural phenomenon. J Membr Sci. 2002;201:175-90.

30. Polotskaya G, Pulyalina A, Goikhman M, Podeshvo I, Valiena I, Toikka A. Aromatic copolyamides with anthrazoline units in the backbone: Synthesis, characterization, pervaporation application. Polymers. 2016;8:362.

31. Martin EC, Kelly LT. US Patent 2981730; 1961.

32. Martin EC, Binning RC, Adams LM, Lee RJ. US Patent 3150456; 1964

33. Garcia Villaluenga JP, Tabe-Mohammadi A. A review on the separation of benzene/cyclohexane mixtures by pervaporation processes. J Membr Sci. 2000;169:159-74.

34. Aouak T, Alghamdi AA, Alrashdi AA, Ouladsmane M, Alam MM, AlOthman Z, Naushad M. Miscibility enhancement of poly(vinyl chloride)/polystyrene blend: Application to membrane separation of benzene from benzene/ cyclohexane mixture by pervaporation. Sep Sci Tech. 2016;51:2440-54.

35. Liu H, Wang N, Zhao C, Ji S, Li J. Membrane materials in the pervaporation separation of aromatic-aliphatic hydrocarbon mixtures- a review. Chin J Chem Eng. 2018:26:1-16.

36. Brun JP. Process for separating hydrocarbons. US patent 3930990; 1976.
37. Mulder MHV, Smolders CA. Separation of isomeric xylenes by pervaporation through cellulose ester membranes. J Membr Sci. 1982;11:349-63.

38. Nair S, Lai Z, Nikolakis V, George X, Griselda B, Tsapatsis M. Separation of close-boiling hydrocarbon mixtures by MFI and FAU membranes made by secondary growth. Micropor Mesopor Mater. 2001;48:219-28.

39. Schleiffelder M, Claudia SB. Crosslinkable copolyimides for the membrane-based separation of $p$-/o-xylene mixtures. React Funct Polym. 2001;49:205-13.

40. Zheng $\mathrm{H}$, Yoshikawa M. Molecularly imprinted cellulose membranes for pervaporation separation of xylene isomers. J Membr Sci. 2015;478:148-54.

41. Yan Y, Davis ME, Gavalas GR. Preparation of zeolite ZSM-5 membranes by in-situ crystallization on porous .a- $\mathrm{Al}_{2} \mathrm{O}_{3}$. Ind Eng Chem Res. 1995;34:165261.

42. Flanders $\mathrm{CL}$, Tuan VA, Noble RD, Falconer JL. Separation of C6 isomers by vapor permeation and pervaporation through ZSM-5 membranes. J Membr Sci. 2000;176:43-53.

43. Fleming HL. Membrane pervaporation: separation of organic/aqueous mixtures. Sep Sci Tech. 1990;25:1239-55.

44. Kuráň $P$, Soják L. Environmental analysis of volatile organic compounds in water and sediment by gas chromatography. J Chromatogr A. 1996;733: 119-41.

45. Peng M, Vane LM, Liu SX. Recent advances in VOCs removal from water by pervaporation. J Hazardous Mater. 2003;98:69-90.

46. Cole CA, Genetelli EJ. Pervaporation of volatile pollutants from water using selective hollow fibers. J (Water Pollution Control Federation). 1970;42:R290-

47. Kondo M, Sato $\mathrm{H}$. Treatment of wastewater from phenolic resin process by pervaporation. Desalination. 1994:98:147-54.

48. Jian K, Pintauro PN, Ponangi R. Separation of dilute organic/water mixtures with asymmetric poly(vinylidene fluoride) membranes. J Membr Sci. 1996; 117:177-33

49. Yeom CK, Kim HK, Rhim JW. Removal of trace VOCs from water through PDMS membranes and analysis of their permeation behaviors. J Appl Polym Sci. 1999;73:601-11.

50. Khayet M, Chowdhury G, Matsuura T. Surface modification of polyvinylidene fluoride pervaporation membranes. AiChE J. 2002:48:2833-43.

51. Uragami T, Ohshima T, Miyata T. Removal of benzene from an aqueous solution of dilute benzene by various cross-linked poly(dimethylsiloxane) membranes during pervaporation. Macromolecules. 2003;36:9430-6.

52. Claes $S$, Vandezande $P$, Mullens $S$, Adriaensens $P$, Peeters $R$, Maurer FHJ, Van Bael MK. Crosslinked poly[1-(trimethylsilyl)-1-propyne] membranes: Characterization and pervaporation of aqueous tetrahydrofuran mixtures. J Membr Sci. 2012;389:459-69.

53. Liu S, Liu G, Zhao X, Jin W. Hydrophobic-ZIF-71 filled PEBA mixed matrix membranes for the recovery of biobutanol via pervaporation. J Membr Sci. 2013;446:181-8

54. Zhou H, Su Y, Chen X, Luo J, Wan Y. High-performance PDMS membranes for pervaporative removal of VOCs from water: The role of alkyl grafting. J Appl Polym Sci. 2016:133:43700.

55. Urtiaga AM, Gorri ED, Beasley JK, Ortiz I. Mass transfer analysis of the pervaporative separation of chloroform from aqueous solution in hollow fiber devices. J Membr Sci. 1999;156:275-91.

56. Hitchens L, Vane LM, Alvares FR. VOC removal from water and surfactant solutions by pervaporation: a pilot study. Sep Purif Tech. 2001;24:67-84.

57. Vane LM, Hitchens L, Alvares FR, Giroux EL. Field demonstration of pervaporation for the separation of volatile organic compounds from the surfactant-based soil remediation fluid. J Hazardous Mater. 2001;81:141-66.

58. Volkov AV, Volkov W, Khotimsjii VS. Membranes based on poly[(1trimethylsilyl)-1-propyne] for liquid-liquid separation. Polym Sci Ser A. 2009; 51:1367.

59. Liu GP, Wang W, Jin WQ. Pervaporation Membranes for Biobutanol Production. ACS Sust Chem Eng. 2014:2:546-60.

60. Van Hecke W, Joossen-Meyvis E, Beckers H, De Wever H. Prospects \& potential of biobutanol production integrated with organophilic pervaporation - A techno-economic assessment. Appl Energy. 2018;228:43749.

61. Chianese A, Zinnamosca F. Ethanol dehydration by azeotropic distillation with a mixed-solvent entrainer. Chem Eng J. 1990:43:59-65.

62. Arifin S, Chien L. Design and control of an isopropyl alcohol dehydration process via extractive distillation using dimethyl sulfoxide as an entrainer. Ind Eng Chem Res. 2008;47:790-803. 
63. Aniya V, De D, Satyavathi B. Comprehensive approach towards dehydration of tert-butyl alcohol by extractive distillation: Entrainer selection, thermodynamic modeling and process optimization. Ind Eng Chem Res. 2016:55:6982-95.

64. Chapman PD, Oliveira T, Livingston AG, Li K. Membranes for the dehydration of solvents by pervaporation. J Membr Sci. 2008;318:5-37.

65. Urtiaga AM, Gorri ED, Gómez P, Casado C, Ibáñez R, Ortiz I. Pervaporation technology for the dehydration of solvents and raw materials in the process industry. Drying Technol. 2007;25:1819-28.

66. Bolto $B$, Hoang $M$, Xie $Z$. A review of membrane selection for the dehydration of aqueous ethanol by pervaporation. Chem Eng Process Process Intensif. 2011;50:227-35.

67. Fazlifard S, Mohammadi T, Bakhtiari O. Chitosan/ZIF-8 mixed-matrix membranes for the pervaporation dehydration of isopropanol. Chem Eng Tech. 2017:40:648-55.

68. Wang X, Jiang J, Liu D, Xue Y, Zhang C, Gu X. Evaluation of hollow fiber Ttype zeolite membrane modules for ethanol dehydration. Chin J Chem Eng. 2017;25:581-6.

69. Kwon Y, Chaudhari S, Kim C, Son D, Park J, Moon M, Shon M, Park Y, Nam S. Ag-exchanged NaY zeolite introduced polyvinyl alcohol/polyacrylic acid mixed matrix membrane for pervaporation separation of water/isopropanol mixture. RCS Adv. 2018;37:20669-78.

70. Langari S, Saljoughi E, Mousavi SM. Chitosan/polyvinyl alcohol/amino functionalized multiwalled carbon nanotube pervaporation membranes: Synthesis, characterizatioin, and performance. Polym Adv Tech. 2018;29:84-94.

71. Xie H, Ji C, Xue S, Xu Z, Yang H, Ma X. Enhanced pervaporation performance of SA-PFSA/ceramic hybrid membranes for ethanol dehydration. Sep Purif Tech. 2018;206:218-25.

72. Xu YM, Tang YP, Chung T-S, Weber M, Maletzko C. Polyarylether membranes for dehydration of ethanol and methanol via pervaporation. Sep Purif Tech. 2018;193:165-74.

73. Krishna Rao KSV, Subha MCS, Sairam M, Mallikarjuna NN, Aminabhavi TM. Blend membranes of chitosan and poly(vinyl alcohol) in pervaporation dehydration of isopropanol and tetrahydrofuran. J Appl Polym Sci. 2007;103: $1918-26$.

74. Zhang W, Li G, Fang Y, Wang X. Maleic anhydride surface-modification of crosslinked chitosan membrane and its pervaporation performance. J Membr Sci. 2007:295:130-8

75. Han Y, Wang K, Lai J, Liu Y. Hydrophilic chitosan-modified polybenzoimidazole membranes for pervaporation dehydration of isopropanol aqueous solutions. J Membr Sci. 2014;463:17-23.

76. Uragami T, Saito T, Miyata T. Pervaporation dehydration characteristics of an ethanol/water azeotrope through various chitosan membranes. Carbohydrate Polymers. 2015;120:1-6.

77. Huang RYM, Pal R, Moon GY. Crosslinked chitosan composite membrane for the pervaporation dehydration of alcohol mixtures and enhancement of structural stability of chitosan/polysulfone composite membranes. J Membr Sci. 1999;160:17-30.

78. Jiraratananon R, Chanachai A, Huang RYM, Uttapap D. Pervapration dehydration of ethanol-water mixtures with chitosan/hydroxyethylcellulose (CS/HEC) composite membranes: I. Effect of operating conditions. J Membr Sci. 2002;195:143-51.

79. Zhang Y, Chen S, Shi R, Du P, Qiu X, Gu X. Pervaporation dehydration of acetic acid through hollow fiber supported DD3R zeolite membrane. Sep Purif Tech. 2018:204:234-42.

80. Huang RYM, Pal R, Moon GY. Pervaporation dehydration of aqueous ethanol and isopropanol mixtures through alginate/chitosan two ply composite membranes supported by poly(vinylidene fluoride) porous membrane. J Membr Sci. 2000;167:275-89.

81. Ball IJ, Huang S, Wolf RA, Shimano JY, Kaner RB. Pervaporation studies with polyaniline membranes and blends. J Membr Sci. 2000;174:161-76.

82. Hosseini S, Charkhi A, Minuchehr A, Ahmadi SJ. Dehydration of acetonitrile using cross-linked sodium alginate membrane containing nano-sized $\mathrm{NaA}$ zeolite. Chemical Papers. 2017;71:1143-53.

83. Masuda T, Isobe E, Higashimura T, Takada K. Poly[1-(trimethylsilyl)-1propyne]: a new high polymer synthesized with transition-metal catalysts and characterized by extremely high gas permeability. J Amer Chem Soc. 1983:105:7473-4

84. Kang YS, Shin EM, Jung B, Kim J. Composite membranes of poly(1trimethylsilyl-1 propyne) and poly(dimethylziloxane) and their pervaporation properties for ethanol-water mixture. J Appl Polym Sci. 1994;53:317.
85. Fadeev AG, Meagher MM, Kelley SS, Volkov W. Fouling of poly[-1-(trimethylsilyl)1-propyne] membranes in pervaporative recovery of butanol from aqueous solutions and ABE fermentation broth. J Membr Sci. 2000;173:133-44.

86. Sing KSW, Everett DH, Haul RAW, Moscou L, Pierotti RA, Rouquerol J, Siemieniewska T. Reporting physisorption data for gas/solid systems with special reference to the determination of surface area and porosity (Recommendations 1984). Pure Appl Chem. 1985;57:603-19.

87. Ninitch OM, Fenelonov VB, Lapkin AA, Okkel LG, Terskikh W, Zamaraev KI. Intrinsic microporosity and gas transport in polyphenylene oxide polymers. Micropor Mesopor Mater. 1999:31:97-110.

88. McKeown NB, Budd PM. Polymers of Intrinsic Microporosirty. In: Encyclopedia of Polymer Science and Technology. USA: Wiley; 2009.

89. Satilmis B, Budd PM. Base-catalysed hydrolysis of PIM-1: amide versus carboxylate formation. RSC Adv. 2014;4:52189-98.

90. Mason CR, Maynard-Atem L, Al-Harbi NM, Budd PM, Bernardo P, Bazzarelli F, Clarizia G, Jansen JC. Polymer of Intrinsic Microporosity Incorporating Thioamide Functionality: Preparation and Gas Transport Properties. Macromolecules. 2011:44:6471-9.

91. Du N, Park HB, Robertson GP, Dal-Cin MM, Visser T, Scoles L, Guiver MD. Polymer nanosieve membranes for $\mathrm{CO}_{2}$-capture applications. Nat Mater. 2011:10:372-5.

92. Du N, Robertson GP, Dal-Cin MM, Scoles L, Guiver MD. Polymers of intrinsic microporosity (PIMs) substituted with methyl tetrazole. Polymer. 2012;53:4367-72

93. Mason CR, Maynard-Atem L, Heard KWJ, Satilmis B, Budd PM, Friess K, Lanc $M$, Bernardo $P$, Clarizia $G$, Jansen JC. Enhancement of $\mathrm{CO}_{2}$ Affinity in a Polymer of Intrinsic Microporosity by Amine Modification. Macromolecules. 2014:47:1021-9.

94. Satilmis B, Alnajrani MN, Budd PM. Hydroxyalkylaminoalkylamide PIMs: Selective Adsorption by Ethanolamine- and Diethanolamine-Modified PIM-1. Macromolecules. 2015:48:5663-9.

95. Ghanem BS, Hashem M, Harris KDM, Msayib KJ, Xu M, Budd PM, Chaukura N, Book D, Tedds S, Walton A, et al. Triptycene-based polymers of intrinsic microporosity: Organic materials that can be tailored for gas adsorption. Macromolecules. 2010;43:5287-94.

96. Fritsch D, Bengtson G, Carta M, McKeown NB. Synthesis and gas permeation properties of spirobischromane-based polymers of intrinsic microporosity. Macromol Chem Phys. 2011;212:1137-46.

97. Bezzu CG, Carta M, Tonkins A, Jansen JC, Bernardo P, Bazzarelli F, Mckeown NB. A spirobifluorene-based polymer of intrinsic microporosity with improved performance for gas separation. Adv Mater. 2012;24:5930-3.

98. Rose I, Bezzu CG, Carta M, Comesaña-Gándara B, Lasseuguette E, Ferrari MC, Bernardo P, Clarizia G, Fuoco A, Jansen JC, et al. Polymer ultrapermeability from the inefficient packing of 2D chains. Nature Mater. 2017;16:932-7.

99. Liu Y, C. P, Ding M, Xu J. Gas permeability and permselectivity of polyimides prepared from phenylenediamines with methyl substitution at the ortho postion. Polym Int. 1999;48:832-836.

100. Ghanem BS, McKeown NB, Budd PM, Selbie JD, Fritsch D. High-performance membranes from polyimides with intrinsic microporosity. Adv Mater. 2008; 20:2766-71

101. Rogan Y, Malpass-Evans R, Carta M, Lee M, Jansen JC, Bernardo P, Clarizia G, Tocci E, Friess $K$, Lanč $M$, et al. A highly permeable polyimide with enhanced selectivity for membrane gas separations. J Mater Chem A. 2014;2:4874-7.

102. Lee M, Bezzu CG, Carta M, Bernardo P, Clarizia G, Jansen JC, McKeown NB. Enhancing the gas permeability of Tröger's base derived polyimides of intrinsic microporosity. Macromolecules. 2016;49:4147-54.

103. Sydlik SA, Chen Z, Swager TM. Triptycene polyimides: Soluble polymers with high thermal stability and low refractive indices. Macromolecules. 2011;44:976-80.

104. Ghanem BS, McKeown NB, Budd PM, Al-Harbi NM, Fritsch D, Heinrich K, Starannikova L, Tokarev A, Yampolskii Y. Synthesis, Characterization, and Gas Permeation Properties of a Novel Group of Polymers with Intrinsic Microporosity: PIM-Polyimides. Macromolecules. 2009;42:7881-8.

105. Ghanem BS, Swaidan R, Litwiller E, Pinnau I. Ultra-microporous Triptycenebased polyimide membranes for high-performance gas separation. Adv Mater. 2014:26:3688-92.

106. Tröger J. Ueber einige mittelst nascirenden formaldehydes entstehende basen. J für Praktische Chemie. 1887;36:225-245.

107. Spielman MA. The Structure of Troeger's Base. J Amer Chem Soc. 1935;57: 583-5.

108. Larson SB, Wilcox CS. Structure of 5,11-methano-2,8-dimethyl-5,6,11,12tetrahydrodibenzo[b,f][1,5]diazocine (Troger's base) at $163 \mathrm{~K}$. Acta Crystallogr Sect C. 1986:42:224-7 
109. Carta M, Malpass-Evans R, Croad M, Rogan Y, Jansen JC, Bernardo P, Bazzarelli F, Mckeown NB. An Efficient Polymer Molecular Sieve for Membrane Gas Separations. Science. 2013;339:303-7.

110. Carta M, Croad M, Malpass-Evans R, Jansen JC, Bernardo P, Clarizia G, Friess K, Lanč M, McKeown NB. Triptycene induced enhancement of membrane gas selectivity for microporous Tröger's base polymers. Adv Mater. 2014;26:3526-31.

111. Rose I, Carta M, Malpass-Evans R, Ferrari MC, Bernardo P, Clarizia G, Jansen JC, McKeown NB. Highly permeable benzotriptycene-based polymer of intrinsic microporosity. ACS Macro Lett. 2015;4:912-5.

112. Yang Z, Zhang H, Yu B, Zhao Y, Ji G, Liu Z. A Tröger's base-derived microporous organic polymer: design and applications in $\mathrm{CO}_{2} / \mathrm{H}_{2}$ capture and hydrogenation of $\mathrm{CO}_{2}$ to formic acid. Chem Commun. 2015;51:1271-4.

113. Williams R, Burt LA, Esposito E, Jansen JC, Tocci E, Rizzuto C, Lanč M, Carta M, McKeown NB. A highly rigid and gas selective methanopentacene-based polymer of intrinsic microporosity derived from Tröger's base polymerization. J Mater Chem A. 2018;6:5661-7.

114. Wang ZG, Liu X, Wang D, Jin J. Tröger's base-based copolymers with intrinsic microporosity for $\mathrm{CO}_{2}$ separation and effect of Tröger's base on separation performance. Polym Chem. 2014:5:2793-800.

115. Carta M, Bezzu CG, Vile J, Kariuki BM, McKeown NB. Polymers of intrinsic microporosity derived from a carbocyclic analogue of Tröger's base. Polymer. 2017;126:324-9.

116. Budd PM, Msayib KJ, Tettershall CE, Ghanem BS, Reynolds KJ, McKeown NB, Fritsch D. Gas separation membranes from polymers of intrinsic microporosity. J Membr Sci. 2005;251:263-9.

117. Robeson LM. Correlation of separation factor versus permeability for polymeric membranes. J Membr Sci. 1991;62:165-85.

118. Robeson LM. The upper bound revisited. J Membr Sci. 2008;320:390-400

119. Ghanem BS, Swaidan R, Ma X, Litwiller E, Pinnau I. Energy-efficient hydrogen separation by AB-type ladder-polymer molecular sieves. Adv Mater. 2014;26: 6696-700.

120. Swaidan R, Al-Saeedi M, Ghanem BS, Litwiller E, Pinnau I. Rational design of intrinsically ultramicroporous polyimides containing bridgehead-substituted triptycene for highly selective and permeable gas separation membranes. Macromolecules. 2014;47:5104-14.

121. Ma X, Ghanem BS, Salines O, Litwiller E, Pinnau I. Synthesis and effect of physical aging on gas transport properties of a microporous polyimide derived from a novel spirobifluorene-based dianhydride. ACS Macro Lett. 2015;4:231-5.

122. Bezzu CG, Carta M, Ferrari MC, Jansen JC, Monteleone M, Esposito E, Fuoco A, Hart KE, Liyana-Arachchi TP, Colina CM, et al. The synthesis, chain-packing and long-term gas permeability of highly selective spirobifluorene-based polymers of intrinsic microporosity. J Mater Chem A. 2018;6:10507-14.

123. Swaidan R, Ghanem BS, Pinnau I. Fine-tuned intrinsically ultramicroporous polymers redefine the permeability/selectivity upper bounds of membranebased air and hydrogen separations. ACS Macro Lett. 2015;4:947-51.

124. Yampolskii Y. Polymeric gas separation membranes. Macromolecules. 2012; 45:3298-311.

125. Adewole JK, Ahmad AL, Ismail S, Leo CP. Current challenges in membrane separation of $\mathrm{CO}_{2}$ from natural gas: A review. Int J Greenhouse Gas Contr. 2013;17:46-65

126. Murali RS, Sankarshana T, Sridhar S. Air separation by polymer-based membrane technology. Sep Purif Rev. 2013:42:130-86.

127. Sanders DF, Smith ZP, Guo R, Robeson LM, McGarth JE, Paul DR, Freeman $\mathrm{BD}$. Energy-efficient polymeric gas separation membranes for a sustainable future: A review. Polymer. 2013;54:4729-61.

128. Pang SH, Jue ML, Leisen J, Jones CW, Lively RP. PIM-1 as a solutionprocessable "molecular basket" for $\mathrm{CO}_{2}$ capture from dilute sources. ACS Macro Lett. 2015;4:1415-9.

129. Ramimoghadam D, MacA Gray E, Webb CJ. Review of polymers of intrinsic microporosity for hydrogen storgae applications. Int J Hydrogen Energy. 2016:41:16944-65

130. Budd PM, Ghanem BS, Msayib KJ, McKeown NB, Tattershall CE. A nanoporous network polymer derived from hexaazatrinaphthylene with potential as an adsorbent and catalyst support. J Mater Chem. 2003;13:2721-6.

131. McKeown NB, Budd PM. Polymers of intrinsic microporosity (PIMs): organic materials for membrane separations, heterogeneous catalysis and hydrogen storage. Chem Soc Rev. 2006;35:675-83.

132. Mackintosh HJ, Budd PM, McKeown NB. Catalysis by microporous phthalocyanine and porphyrin network polymers. J Mater Chem. 2008;18: 573-8.
133. Kaur P, Hupp JT, Nguyen ST. Porous organic polymers in catalysis: Opportunities and challenges. ACS Catal. 2011;1:819-35.

134. Carturan S, Antonaci A, Maggioni G, Quaranta A, Tonezzer M, Milan R, Della Mea G. Optical vapors sensing capabilities of polymers of intrinsic microporosity. In: Malcovati P, Baschirotto P, d'Amico A, Natale CD, editors. Sensors and Microsystems: Dordrecht: Springer; 2009. p. 55-8.

135. Rakow NA, Wendland MS, Trend JE, Poirier RJ, Paolucci DM, Maki SP, Lyons CS, Swierczek MJ. Visual indicator for trace organic volatiles. Langmuir. 2010; 26:3767-70.

136. Thomas JC, Trend JE, Rakow NA, Wendland MS, Poirier RJ, Paolucci DM. Optical sensor for diverse organic vapors at ppm concentration ranges. Sensors. 2011;11:3267-80.

137. Allen MJ, Tung VC, Kaner RB. Honeycomb carbon: a review of graphene. Chem Rev. 2010;110:132-45.

138. Lu X, Yu M, Huang H, Ruoff RS. Tailoring graphite with the goal of achieving single sheets. Nanotech. 1999;10:269-72.

139. Wallace PR. The band theory of graphite. Phys Rev. 1947;71:622-34.

140. Dimiev AM, Tour JM. Mechanism of graphene oxide formation. ACS nano. 2014;8:3060-8

141. Bharech S, Kumar R. A review on the properties and applications of graphene. J Mater Sci Mech Eng. 2015;2:70-3.

142. Schuth F, Sing KSW, Weitkamp J. Handbook of porous solids: Wiley-VCH; 2008.

143. Ray AB. Activated carbon. Ind Eng Chem. 1940;32:1166-7.

144. Choi W, Lahiri I, Seelaboyina R, Kang YS. Synthesis of graphene and its applications: a review. Crit Rev Solid State Mater Sci. 2010;35:52-71.

145. Ren S, Rong P, Yu Q. Preparations, properties and applications of graphene in functional devices: a concise review. Ceramics Int. 2018;44:11940-55.

146. Liu G, Jin W, Xu N. Graphene-based membranes. Chem Soc Rev. 2015;44: 5016-30.

147. Nair RR, Wu HA, Jayaram PN, Grigorieva IV, Geim AK. Unimpeded Permeation of Water Through Helium-Leak-Tight Graphene-Based Membranes. Science. 2012:335:442-4

148. Joshi RK, Carbone P, Wang FC, Kravets VG, Su Y, Grigorieva IV, Wu HA, Geim AK, Nair RR. Precise and Ultrafast Molecular Sieving Through Graphene Oxide Membranes. Science. 2014;343:752-4.

149. Abraham J, Vasu KS, Williams CD, Gopinadhan K, Su Y, Cherian CT, Dix J, Prestat E, Haigh SJ, Grigorieva IV, et al. Tunable sieving of ions using graphene oxide membranes. Nature Nanotech. 2017;12:546-50.

150. Zhou KG, Vasu KS, Cherian CT, Neek-Amal M, Zhang JC, GhorbanfekrKalashami H, Huang K, Marshall OP, Kravets VG, Abraham J, et al. Electrically controlled water permeation through graphene oxide membranes. Nature. 2018;559:236-40.

151. Yang Q, Su Y, Chi C, Cherian CT, Huang K, Kravets VG, Wang FC, Zhang JC, Pratt A, Grigorenko AN, et al. Ultrathin graphene-based membrane with precise molecular sieving and ultrafast solvent permeation. Nature Mater. 2017; 16:1198-202

152. Yeh T-M, Wang Z, Mahajan D, Hsiao BS, Chu B. High flux ethanol dehydration using nanofibrous membranes containing graphene oxide barrier layers. J Mater Chem A. 2013;1:12998-3003.

153. Tang YP, Paul DR, Chung TS. Free-standing graphene oxide thin films assembled by a pressurized ultrafiltration method for dehydration of ethanol. J Membr Sci. 2014;458:199-208.

154. Li G, Shi L, Zeng G, Zhang Y, Sun Y. Efficient dehydration of the organic solvents through graphene oxide (GO)/ceramic composite membranes. RSC Adv. 2014:4:52012-5.

155. Hung W-S, Tsou C-H, De Guzman M, An Q-F, Liu Y-L, Zhang Y-M, Hu C-C, Lee K-R, Lai J-Y. Cross-Linking with Diamine Monomers To Prepare Composite Graphene Oxide-Framework Membranes with Varying d-Spacing. Chem Mater. 2014:26:2983-90

156. W-s H, Lee K-r, J-y L. Effect of microstructure of graphene oxide fabricated composite membranes on alcohol dehydration. Adv Mater Res. 2014;1051:278-82.

157. Chen X, Liu G, Zhang H, Fan Y. Fabrication of graphene oxide composite membranes and their application for pervaporation dehydration of butanol. Chin J Chem Eng. 2015;23:1102-9.

158. Tsou C-H, An Q-F, Lo S-C, De Guzman M, Hung W-S, Hu C-C, Lee K-R, Lai J$Y$. Effect of microstructure of graphene oxide fabricated through different self-assembly techniques on 1-butanol dehydration. J Membr Sci. 2015;477: 93-100.

159. Liang B, Zhan W, Qi G, Lin S, Nan Q, Liu Y, Cao B, Pan K. High performance graphene oxide/polyacrylonitrile composite pervaporation membranes for desalination applications. J Mater Chem A. 2015;3:5140-7. 
160. Cheng C, Shen L, Yu X, Yang Y, Li X, Wang X. Robust construction of a graphene oxide barrier layer on a nanofibrous substrate assisted by the flexible poly (vinylalcohol) for efficient pervaporation desalination. J Mater Chem A. 2017;5:3558-68.

161. Ying Y, Liu D, Zhang W, Ma J, Huang H, Yang Q, Zhong C. High-Flux Graphene Oxide Membranes Intercalated by Metal-Organic Framework with Highly Selective Separation of Aqueous Organic Solution. ACS Appl Mater Interf. 2017;9:1710-8.

162. Qin Z, Wang L, Zhang W, Pan K. A novel surface crosslinked GO-based membrane with superior separation performance. RSC Adv. 2017;7:5421321.

163. Lecaros RLG, Mendoza GEJ, Hung W-S, An Q-F, Caparanga AR, Tsai H-A, Hu C-C, Lee K-R, Lai J-Y. Tunable interlayer spacing of composite graphene oxide-framework membrane for acetic acid dehydration. Carbon. 2017;123: 660-7.

164. Hua D, Rai RK, Zhang Y, Chung T-S. Aldehyde functionalized graphene oxide frameworks as robust membrane materials for pervaporative alcohol dehydration. Chem Eng Sci. 2017;161:341-9.

165. Zhao D, Zhao J, Ji Y, Liu G, Liu S, Jin W. Facilitated water-selective permeation via PEGylation of graphene oxide membrane. J Membr Sci. 2018:567:311-20.

166. Boffa V, Etmimi H, Mallon PE, Tao HZ, Magnacca G, Yue YZ. Carbon-based building blocks for alcohol dehydration membranes with disorderenhanced water permeability. Carbon. 2017;118:458-66.

167. Van Gestel T, Barthel J. New types of graphene-based membranes with molecular sieve properties for $\mathrm{He}_{1} \mathrm{H}_{2}$ and $\mathrm{H}_{2} \mathrm{O}$. J Membr Sci. 2018;554:378-84

168. Guan K, Liu Q, Ji Y, Zhang M, Wu Y, Zhao J, Liu G, Jin W. Precisely Controlling Nanochannels of Graphene Oxide Membranes through LigninBased Cation Decoration for Dehydration of Biofuels. ChemSusChem. 2018; 11:2315-20.

169. Suhas DP, Raghu AV, Jeong HM, Aminabhavi TM. Graphene-loaded sodium alginate nanocomposite membranes with enhanced isopropanol dehydration performance via a pervaporation technique. RSC Adv. 2013;3: 17120-30.

170. Wang $M$, Pan F, Yang L, Song $Y$, Wu H, Cheng $X$, Liu G, Yang $H$, Wang $H$, Jiang $Z$, et al. Graphene oxide quantum dots incorporated nanocomposite membranes with high water flux for pervaporative dehydration. J Membr Sci. 2018:563:903-13.

171. Dharupaneedi SP, Anjanapura RV, Han JM, Aminabhavi TM. Functionalized Graphene Sheets Embedded in Chitosan Nanocomposite Membranes for Ethanol and Isopropanol Dehydration via Pervaporation. Ind Eng Chem Res. 2014;53:14474-84.

172. Lin Y-K, Nguyen V-H, Yu JC-C, Lee C-W, Deng Y-H, Wu JCS, Wu KCW, Tung $K-L$, Chen C-L. Biodiesel production by pervaporation-assisted esterification and pre-esterification using graphene oxide/chitosan composite membranes. J Taiwan Inst Chem Eng. 2017;79:23-30.

173. Hung W-S, Chang S-M, Lecaros RLG, Ji Y-L, An Q-F, Hu C-C, Lee K-R, Lai J-Y. Fabrication of hydrothermally reduced graphene oxide/chitosan composite membranes with a lamellar structure on methanol dehydration. Carbon. 2017;117:112-9.

174. Manshad S, Sazegar MR, Mohd Nawawi MG, Hassan HB. Fabrication of nanohybrid polyetherimide/graphene oxide membranes: biofuel dehydration by pervaporation process. RSC Adv. 2016;6:103888-94.

175. Salehian P, Chung T-S. Thermally treated ammonia functionalized graphene oxide/polyimide membranes for pervaporation dehydration of isopropanol. J Membr Sci. 2017:528:231-42.

176. Wang N, Ji S, Zhang G, Li J, Wang L. Self-assembly of graphene oxide and polyelectrolyte complex nanohybrid membranes for nanofiltration and pervaporation. Chem Eng J. 2012;213:318-29.

177. Khodadadi Dizaji A, Mortaheb HR, Mokhtarani B, Rahmani S. Pervaporative performance of polydimethylsiloxane-graphene/polyethersulfone hybrid membrane: Effects of graphene structure and surface properties. Chem Eng Res Des. 2017;124:181-92.

178. Wang N, Ji S, Li J, Zhang R, Zhang G. Poly (vinyl alcohol)-graphene oxide nanohybrid "pore-filling" membrane for pervaporation of toluene/n-heptane mixtures. J Membr Sci. 2014;455:113-20.

179. Khazaei A, Mohebbi V, Behbahani RM, Ramazani S. A A. Poly (Vinyl Alcohol)/ Graphene Oxide Mixed Matrix Membranes for Pervaporation of Toluene and Isooctane. Polym-Plast Technol Eng. 2017;56:1286-94.

180. Khazaei A, Mohebbi V, Behbahani RM, Ahmad Ramazani SA. Pervaporation of toluene and iso-octane through poly(vinyl alcohol)/graphene oxide nanoplate mixed matrix membranes: Comparison of crosslinked and noncrosslinked membranes. J Appl Polym Sci. 2018;135(Article 45853):9.

181. Maya MG, George SC, Jose T, Thomas S. Polychloroprene rubber/reduced graphene oxide (RGO) nanomembranes for pervaporation separation of azeotropic mixtures. J Membr Sep Technol. 2014;3:178-84 177pp.

182. Wu XM, Zhang QG, Soyekwo F, Liu LQ, Zhu AM. Pervaporation removal of volatile organic compounds from aqueous solutions using the highly permeable PIM-1 membrane. AiChE J. 2015;62:842-51.

183. Adymkanov SV, Yampol'skii YP, Polyakov AM, Budd PM, Reynolds KJ McKeown NB, Msayib KJ. Pervaporation of alcohols through highly permeable PIM-1 polymer films. Polym Sci Ser A. 2008;50:444-50.

184. Mason CR, Buonomenna MG, Golemme G, Budd PM, Galiano F, Figoli A, Friess K, Hynek V. New organophilic mixed matrix membranes derived from a polymer of intrinsic microporosity and silicalite-1. Polymer. 2013;54:2222-30.

185. Alberto M, Luque-Alled JM, Gao L, lliut M, Prestat E, Newman L, Haigh SJ, Vijayaraghavan A, Budd PM, Gorgojo P. Enhanced organophilic separations with mixed matrix membranes of polymers of intrinsic microporosity and graphene-like fillers. J Membr Sci. 2017;526:437-49.

186. Bennett M, Brisdon BJ, England R, Field RW. Performance of PDMS and organifunctionalised PDMS membranes for the pervaporative recovery of organics from aqueous streams. J Membr Sci. 1997;137:63-88.

187. Yuanzuo L, Yingxin W, Zheng G, Xuepeng Q. Research platform model for separation of ethanol-water solution by membrane pervaporation according to 1-trimethylsilic. J Funct Polym. 1998;11:34-8.

188. Žák M, Klepic M, Štastná LČ, Sedláková Z, Vychodilová H, Hovorka Š, Friess K, Randová A, Brožová L, Jansen JC, et al. Selective removal of butanol from aqueous solution by pervaporation with a PIM-1 membrane and membrane aging. Sep Purif Tech. 2015;151:108-14

189. Shi Q, Zhang K, Lu R, Jiang J. Water desalination and biofuel dehydration through a thin membrane of polymer of intrinsic microporosity: Atomistic simulation study. J Membr Sci. 2018;545:49-56.

190. Wu XM, Guo H, Soyekwo F, Zhang QG, Lin CX, Liu QL, Zhu AM. Pervaporation Purification of Ethylene Glycol Using the Highly Permeable PIM-1 Membrane. J Chem Eng Data. 2015;61:579-86.

191. Chen M, Wu X, Soyekwo F, Zhang Q, Lv R, Zhu A, Liu Q. Toward improved hydrophilicity of polymers of intrinsic microporosity for pervaporation dehydration of ethylene glycol. Sep Purif Tech. 2017;174:166-73.

192. Bekir S, Budd PM. Base-catalysed hydrolysis of PIM-1: amide versus carboxylate formation. RCS Adv. 2014;4:52189-98.

193. Bekir S, Budd PM, Uyar T. Systematic hydrolysis of PIM-1 and electrospinning of hydrolzed PIM-1 ultrafine fibers for an efficient removal of dye from water. React Funct Polym. 2017;121:67-75.

194. Yong WF, Chung T-S. Mechanically Strong and flexible hydrolyzed polymers of intrinsic microporosity (PIM-1) membranes. J Polym Sci Part B Polym Phys. 2017;55:344-54.

195. Yong WF, Salehian P, Zhang L, Chung T-S. Effects of hydrolyzed PIM-1 in polyimide-based membranes on C2-C4 alcohols dehydration via pervaporation. J Membr Sci. 2017:523:430-8

196. Cihal P, Vopicka O, Durdakova T-M, Budd PM, Harrison W, Friess K Pervaporation and vapour permeation of methanol - dimethyl carbonate mixtures through PIM-1 membranes. Sep Purif Technol. 2019;217:206-14.

197. Salehian P, Yong WF, Chung T-S. Development of high performance carboxylated PIM-1/P84 blend membranes for pervaporation dehydration of isopropanol and $\mathrm{CO}_{2} / \mathrm{CH}_{4}$ separation. J Membr Sci. 2016;518:110-9.

198. Zhang G, Cheng H, Su P, Zhang X, Zheng J, Lu Y, Liu Q. PIM-1/PDMS hybrid pervaporation membrane for high-efficiency separation of n-butanol-water mixture under low concentration. Sep Purif Technol. 2019;216:83-91.

199. Althumayri K, Harrison WJ, Shin Y, Gardiner J, Casiraghi C, Budd PM, Bernardo P, Clarizia G, Jansen JC. The influence of few-layer graphene on the gas permeability of the high-free-volume polymer PIM-1. Phil Trans Roy Soc A Math Phys Eng Sci. 2016;374:20150031.

200. Gonciaruk A, Althumayri K, Harrison WJ, Budd PM, Siperstein FR. PIM-1/ graphene composite: A combined experimental and molecular simulation study. Micropor Mesopor Mater. 2015;209:126-34.

201. Shin Y, Prestat E, Zhou K-G, Gorgojo P, Althumayri K, Harrison W, Budd PM, Haigh SJ, Casiraghi C. Synthesis and characterization of composite membranes made of graphene and polymers of intrinsic microporosity. Carbon. 2016:102:357-66.

202. Gao L, Alberto M, Gorgojo P, Szekely G, Budd PM. High-flux PIM-1/PVDF thin film composite membranes for 1-butanol/water pervaporation. J Membr Sci. 2017;529:207-14. 
203. Lan Y, Peng P, Chen P. Preparation of polymers of intrinsic microporosity composite membranes incorporated with modified nano-fumed silica for butanol separation. Adv Polym Technol. 2018:37:3297-3304.

204. Lan Y, Peng P. Preparation of polymer of intrinsic microporosity composite membranes and their applications for butanol recovery. J Appl Polym Sci. 2019;136(Article 46912):9.

205. Alberto M, Bhavsar R, Luque-Alled JM, Prestat E, Gao L, Budd PM, Vijayaraghavan A, Szekely G, Holmes SM, Gorgojo P. Study on the formation of thin film nanocomposite (TFN) membranes of polymers of intrinsic microporosity and graphene-like fillers: Effect of lateral flake size and chemical functionalization. J Membr Sci. 2018;565:390-401.

206. Fritsch D, Merten P, Heinrich K, Lazar M, Priske M. High performance organic solvent nanofiltration membranes: Development and thorough testing of thin film composite membranes made of polymers of intrinsic microporosity (PIMs). J Membr Sci. 2012;401-402:222-31.

207. Moghadam F, Park HB. Two-dimensional materials: an emerging platform for gas separation membranes. Curr Opinion Chem Eng. 2018;20:28-38.

\section{Publisher's Note}

Springer Nature remains neutral with regard to jurisdictional claims in published maps and institutional affiliations.

Ready to submit your research? Choose BMC and benefit from:

- fast, convenient online submission

- thorough peer review by experienced researchers in your field

- rapid publication on acceptance

- support for research data, including large and complex data types

- gold Open Access which fosters wider collaboration and increased citations

- maximum visibility for your research: over $100 \mathrm{M}$ website views per year

At BMC, research is always in progress.

Learn more biomedcentral.com/submissions 